\title{
SANTIAGO DE CHILE DE CARA \\ A LA GLOBALIZACIÓN: ¿OTRA CIUDAD?
}

\author{
Carlos A. de Mattos \\ Pontificia Universidad Católica de Chile
}

RESUMO

Este trabalho propõe-se a identificar e caracterizar a "outra cidade" resultante das transformações que afetaram a área metropolitana de Santiago do Chile em função da assunção, a partir de meados de 1975, de uma nova estratégia macroeconômica, onde tanto uma crescente liberalização econômica, como uma ampla abertura externa, favoreceram a progressiva globalização da economia nacional. Nesse contexto, observa-se como junto a importantes modificações na base econômica metropolitana começou a processarse na grande Santiago uma radical reestruturação de seu mercado de trabalho e uma maior dispersão territorial das atividades produtivas e da população. Nesse novo cenário, analisa-se como as transformações que afetaram a cidade emergente incidiram na afirmação, de um lado, de uma morfologia social donde persiste a polarização social e a segregação residencial e, de outra, de uma morfologia territorial onde impera a periurbanização e a policentralidade, transformações essas que correspondem às tendências que atualmente se observam nas grandes áreas metropolitanas tanto dos países centrais como das economias emergentes.

PALAVRAS-CHAVE: globalização; informalidade; metropolização; periurbanização; policentrismo; segregação residencial.

\section{NUEVA ESTRATEGIA MACROECONÓMICA: LIBERALIZACIÓN Y DESREGULACIÓN}

Ocurre con cierta frecuencia que algunos visitantes que retornan a Santiago después de una ausencia prolongada, al observar el conjunto de cambios producidos durante las últimas décadas en esta ciudad, sinteticen su impresión afirmando que se han encontrado con "otra ciudad". Con ello, aluden a la magnitud de las diferencias percibidas entre la ciudad que conocieron en un pasado no demasiado lejano y la que surgió asociada a las transformaciones ocasionadas por la aplicación de una estrategia macroeconómica

\footnotetext{
1 Este trabajo fue elaborado para ser presentado en el Seminario Internacional "El desafío de las áreas metropolitanas en un mundo globalizado - una mirada a Europa y América Latina", realizado en Barcelona durante los días 4, 5 y 6 de junio del 2002, organizado por el Institut Catala de Cooperacio Iberoamericana, el Institut d'Estudis Territorials de la Universitat Pompeu Fabra y el Instituto de Estudios Urbanos y Territoriales de la Pontificia Universidad Católica de Chile.
}

radicalmente diferente a la de la época de crecimiento hacia adentro vía industrialización sustitutiva de importaciones, que había estado vigente desde la década de los años treinta.

En el ámbito latinoamericano, Chile se ubica como uno de los países que más temprano adoptó políticas basadas en los lineamientos teóricoideológicos de lo que posteriormente se propagó ampliamente bajo la etiqueta del Consenso de Washington y, más popular e imprecisamente, bajo la de "modelo neoliberal". Cuando menos en sus instancias iniciales, estas políticas respondieron a un enfoque sumamente ortodoxo de liberalización económica, ajustado a los dictados de la escuela monetarista de Chicago y, también, a las recomendaciones formuladas por algunos organismos multilaterales (en especial FMI y Banco Mundial) como receta para los países en desarrollo (MELLER, 1996). Cuando algunos años más tarde los gobiernos de Thatcher y de Reagan se inclinaron por este enfoque de política económica en Gran Bretaña y Estados Unidos respectivamente, el mismo se difundió por el mundo entero, adquiriendo el carácter de un nuevo 
"saber convencional dominante" (KRUGMAN, 1996) y tuvo una decisiva incidencia en la gestación de las transformaciones que iban a caracterizar a esta nueva fase modernizadora.

De hecho, estas políticas comenzaron a ser aplicadas sistemáticamente en Chile a partir de julio de 1975 y desde entonces, más allá de algunos cambios de énfasis, la concepción general a la que responden ha mantenido su vigencia hasta el presente. Ello ha ocurrido con sus ejes centrales (liberalización económica, desregulación, subsidiaridad del Estado, apertura externa, flexibilización salarial etc.), aún cuando desde entonces ocurrieron importantes cambios políticos (en especial, fin del Régimen Militar y comienzo de un nuevo período democrático). Más allá de ciertas persistencias y continuidades esenciales, la aplicación de estas políticas provocó un conjunto de rupturas y mutaciones que permiten afirmar que entonces se desencadenó una nueva fase de modernización capitalista en este país.

En ese proceso, la economía chilena recuperó sus principales equilibrios macroeconómicos $\mathrm{y}$ comenzó una fase de sostenido crecimiento que se prolongó desde la mitad de la década de los años 80 hasta finales de la de los 90 . Fue así que entre 1986 y 1998 la tasa media de crecimiento del Producto Interno Bruto (PIB) se situó en alrededor del $7 \%$, con un crecimiento equivalente del sector industrial, lo que estuvo acompañado, entre otros, por un significativo crecimiento de la tasa de inversión que la llevó a alcanzar valores superiores al 30\% del PIB hacia mediados de la década de los noventa, por una progresiva caída de la tasa de inflación y de la tasa de desocupación.

Este exitoso desempeño se interrumpió hacia mediados de 1998 cuando, bajo los impactos de la crisis internacional iniciada en el sudeste asiático, declinó fuertemente el ritmo de crecimiento, cayó la tasa de inversión y comenzaron a aumentar los niveles de desocupación. Sin embargo, los cambios a los que se refiere este trabajo ya se habían materializado, originando un escenario diferente al que había predominado en las décadas precedentes y los elementos básicos de la "otra ciudad" ya estaban configurados. Por ello, en lo que sigue focalizaremos la atención fundamentalmente en las transformaciones ocurridas durante el lapso 1985-1998, en el entendido de que fue en este período que se establecieron los rasgos básicos de esa "otra ciudad" que aquí se intentará caracterizar.
Con el propósito de identificar y caracterizar a esta "otra ciudad", analizaremos las transformaciones que afectaron en este período al Área Metropolitana de Santiago ${ }^{2}$ (AMS), observando en primer término las provocadas por el cambio de estrategia macroeconómica, donde tanto una creciente desregulación compatible con el principio de subsidiaridad estatal, como una amplia apertura externa, favorecieron la progresiva globalización de la economía nacional. Con este punto de partida, observaremos como junto a importantes modificaciones en la arquitectura productiva dominante y en la correspondiente base económica metropolitana, que se fueron procesando asociadas a la globalización, el Gran Santiago comenzó a presenciar una radical reestructuración de su mercado de trabajo y una mayor dispersión territorial de las actividades productivas y de la población, más allá de la mancha metropolitana continua.

Al mismo tiempo, tendremos en cuenta la incidencia del cambio de enfoque de gestión pública $\mathrm{y}$, en particular, de gestión urbana, establecido conforme al principio de subsidiaridad del Estado, sobre las estrategias de los actores urbanos más relevantes desde el punto de vista del impacto de sus decisiones y acciones en la vida y en la morfología urbanas, y como esto incidió en importantes cambios en el funcionamiento y en la estructura metropolitana.

Finalmente, veremos como en este nuevo contexto las transformaciones que afectan a la ciudad emergente incidieron en la afirmación, por una parte, de una morfología social donde persiste la polarización social y la segregación y, por otra parte, de una morfología territorial en la que impera la periurbanización y la policentralidad. Con ello, trataremos de mostrar como estas transformaciones siguen las tendencias que actualmente se están manifestando en las grandes áreas metropolitanas tanto de los países centrales como

\footnotetext{
2 El Area Metropolitana de Santiago (AMS) forma parte de la Región Metropolitana de Santiago (RMS), que es una de las 13 regiones en que está dividido administrativamente el territorio chileno. La RMS está dividida en 5 provincias y en 51 comunas. La Provincia de Santiago está dividida en 32 comunas, las que conjuntamente con las Comunas de Puente Alto (Provincia de Cordillera), San Bernardo (Provincia de Maipo) y Padre Hurtado (Provincia de Talagante) conforman actualmente el AMS o Gran Santiago.
} 
de las economías emergentes.

\section{GLOBALIZACIÓN, NUEVA BASE ECONÓ- MICA METROPOLITANA Y NUEVO ENFO- QUE DE GESTIÓN URBANA}

\section{II.1. Apertura externa, globalización y base económica metropolitana}

La evolución de la economía chilena durante estos años muestra que a medida que se fue restableciendo el equilibrio de las principales cuentas macroeconómicas y cobró impulso una nueva fase de crecimiento, se produjo una progresiva mejoría de la imagen del país en el contexto económico internacional. Esto se tradujo tanto en las respectivas calificaciones de riesgopaís ${ }^{3}$, así como también en los rankings de competitividad, en los que Chile ha logrado ubicarse regularmente por encima del resto de los países latinoamericanos. Fue así que, con relativa rapidez, se logró mejorar el nivel de atractividad de la economía chilena con respecto a unos capitales que entonces intensificaban aceleradamente su movilidad.

De esta manera se profundizó el nivel de articulación de Chile en la dinámica económica internacional, lo cual se reflejó ante todo en los indicadores de comercio internacional: entre 1982 y 1997 las exportaciones de bienes pasaron de 3 710 a 16923 millones de dólares y las importaciones de 3643 a 18218 millones. Al mismo tiempo, y en la misma dirección, se produjo un importante crecimiento de la inversión extranjera directa (IED): mientras que la acumulada durante el período 1974-1989 llegó a US\$ 5105 millones, la correspondiente a 1990-1998 ascendió a US\$ 24594 millones. Pese a la ubicación marginal de la economía chilena en el mundo y a su modesta dimensión, la estabilidad lograda y los niveles de crecimiento alcanzados en este período permitieron que la relación entre IED y PIB para el período 1990-1996 terminase siendo la más elevada entre las economías emergentes latinoamericanas. Otros indicadores apuntan en la misma dirección.

\footnotetext{
3 Así, por ejemplo, en 1991 Chile ya ocupaba el lugar 35 entre 139 países según la Guía Internacional de Riesgo País (El Diario, 27.set.1991). Posteriormente, en 1993, Chile era el país latinoamericano con menor riesgo para invertir de acuerdo según las clasificaciones realizadas por Standard \& Poor y Moody's (El Mercurio, 11.ago.1993).
}

Estos niveles de IED tuvieron como lógica consecuencia un persistente aumento de la participación del capital y de las empresas extranjeras en sectores-clave de la economía nacional, tales como minería, telecomunicaciones, finanzas, electricidad, distribución comercial, consumo, turismo etc. Frente a esta situación, y considerando que, desde el punto de vista económico, la globalización puede entenderse "ante todo [como] una cuestión de integración organizacional, que reposa sobre la coordinación de tareas y de funciones y la movilidad de recursos productivos interdependientes al interior de redes de producción transfronterizas (RPTF)" (GUILHON, 1998, p. 97), se puede concluir que lo que comenzó a desencadenarse en Chile desde mediados de la década de los años setenta fue la progresiva irrupción de diversas redes de este tipo, impulsando con ellos cambios fundamentales en la organización y el funcionamiento de la economía nacional.

Esta transformación debe ser analizada teniendo en cuenta que, como señala Lafay (1996, p. 37ss), en el nuevo escenario son las empresas las que producen y efectúan lo esencial de las relaciones económicas entre los territorios, básicamente mediante tres mecanismos diferentes, el comercio internacional inter-empresas, la inversión directa en el extranjero y la organización internacional en red. Desde esta perspectiva, puede afirmarse que lo que ocurrió en Chile fue que las empresas multinacionales comenzaron a aprovechar las reglas del juego establecidas por la estrategia de liberalización económica que, justamente, establecía como uno de sus objetivos centrales explícitos transformar al capital privado en el protagonista central del proceso de acumulación y crecimiento. En otras palabras, el conjunto de arreglos institucionales que se derivaron de las políticas impulsadas desde 1975 lograron configurar un ámbito especialmente favorable para el arribo y desembarque en territorio chileno de distintos tipos de redes transfronterizas, especialmente productivas, comerciales y financieras, en una evolución que continúa hasta ahora.

De esta manera, al crecer la presencia de estas empresas y actividades en el aparato productivo chileno, comenzó a ganar importancia una nueva arquitectura productiva caracterizada por el predominio de la organización empresarial en red. En su conjunto, estas transformaciones configuran 
lo que Veltz denomina un "modelo celular en red", donde como denominador común se imponen tres evoluciones fundamentales: la descomposición de las grandes empresas integradas verticalmente, la externalización creciente de las actividades consideradas como no estratégicas y la multiplicación al interior de las fábricas de unidades elementales semi-autónomas (VELTZ, 2000, p. $178 \mathrm{ss})$.

A medida que la propia modernización capitalista comenzó a perfilar en Chile un modelo productivo de esta naturaleza, la localización en el AMS de la mayoría de los nodos o eslabones de variadas redes - principalmente productivas, comerciales y financieras - incidió en una profunda transformación de la base económica metropolitana, donde un relativo declive de la industria abrió paso a una ascendente participación de los servicios, todo lo cual continuó acentuando la urbanización de la economía. En especial en sus instancias iniciales, esta transformación estuvo asociada a un irreversible agotamiento de la industria sustitutiva, que había sido el protagonista central de la economía metropolitana por varias décadas.

La progresiva terciarización en este período de la economía nacional y, en particular, de la economía metropolitana, se puede observar en la estructura del PBI y del empleo: en los últimos 20 años la industria disminuyó su aporte al PIB de la RMS desde alrededor del $27 \%$ a alrededor del $20 \%$, en tanto el sector servicios pasó de menos del $62 \%$ a cerca del $70 \%$ (Cuadro 1). En el sector servicios los cambios se observan básicamente en la ganancia de participación de transporte y comunicaciones, servicios financieros, y servicios personales, mientras perdió participación la administración pública (BANCO CENTRAL DE CHILE, 1998). Por otra parte, continuó el repliegue de los sectores que se habían ubicado como sectores líderes a lo largo del período industrialdesarrollista, como es el caso de algunas de las más importantes industrias volcadas al mercado interno, como textiles y metalmecánica, que disminuyeron su participación en el PIB y el empleo, en comparación a la que tenían al comienzo de esta fase.

CUADRO 1 - Cambios en la estructura del PIB de la RMS

\begin{tabular}{|l|r|r|r|r|r|r|}
\hline \multirow{2}{*}{ Sector } & \multicolumn{5}{|c|}{ Promedios trienales (en \%) } \\
\cline { 2 - 7 } & $\mathbf{1 9 6 0 - 6 2}$ & $\mathbf{1 9 7 0 - 7 2}$ & $\mathbf{1 9 8 0 - 8 2}$ & $\mathbf{1 9 8 5 - 8 7}$ & $\mathbf{1 9 9 0 - 9 2}$ & $\mathbf{1 9 9 4 - 9 6}$ \\
\hline Agropecuario, Pesca y Minería & 3,7 & 3,0 & 3,9 & 4,1 & 4,2 & 3,7 \\
\hline Industria & 26,3 & 26,8 & 20,8 & 21,2 & 21,6 & 20,8 \\
\hline Construcción & 8,0 & 5,9 & 6,2 & 4,7 & 5,6 & 5,5 \\
\hline Servicios & 61,9 & 64,3 & 69,0 & 69,8 & 68,7 & 69,9 \\
\hline PAís & 100,0 & 100,0 & 100,0 & 100,0 & 100,0 & 100,0 \\
\hline
\end{tabular}

Fuente: Elaborado con base en CIEPLAN-SUBDERE (1994) y Banco Central de Chile (1998).

Al mismo tiempo se fue constituyendo una industria más moderna y dinámica, con capacidad para competir en un mercado en el que se estaba produciendo una invasión de mercaderías industriales a bajo precio, especialmente de procedencia asiática. En cualquier caso, pese a estas transformaciones, en la industria metropolitana emergente todavía predominan sectores tradicionales orientados a la producción para el mercado interno y al procesamiento de recursos naturales (semimanufacturas) para la exportación, lo que indica que más que en la estructura interindustrial, la modernización se produjo principalmente en el plano organizacional (especialmente externaliza- ción y flexibilización laboral) y en la renovación de maquinaria y equipamientos.

Como consecuencia de estas transformaciones, bajo una persistente urbanización de la economía y de la población, comenzó a reactivarse el crecimiento económico metropolitano que había permanecido estancado por un largo período, recuperando progresivamente el AMS su importancia en el ámbito nacional. En esta situación, junto al desencadenamiento de un nuevo impulso de expansión periurbana, se produjeron diversos cambios en el funcionamiento, la morfología y la apariencia del AMS, iniciando la evolución hacia "otra ciudad". 


\section{II.2. Atractividad y concentración productiva metropolitana}

En lo esencial, tanto los nodos de las redes globales, como las actividades productivas orientadas al mercado interno, escogieron preferentemente al AMS como localización, debido al peso de un conjunto de factores que otorgaron a este lugar mayor atractividad que las restantes ciudades chilenas; en este sentido se destaca la incidencia de mejores y más expeditos sistemas de comunicaciones, la proximidad física de otras empresas importantes, la disponibilidad de servicios a la producción, las condiciones para una amplia y fluida comunicación directa cotidiana, el acceso a una parte significativa del mercado interno, la presencia de contingentes amplios y capacitados de recursos humanos, la existencia de un tejido industrial relativamente diversificado etc. (DE MATTOS, 2001). Tendieron así a localizarse en el Gran Santiago especialmente:

a) las funciones de comando del nuevo poder económico, incluidas las involucradas en el manejo de las relaciones con la economía global, así como en la gestión y coordinación de la parte central del proceso de acumulación, tales como las sedes corporativas y las oficinas centrales de las empresas multinacionales, de los principales grupos económicos chilenos y de las más importantes empresas nacionales;

b) la parte más importante de los servicios a las familias (comercio, educación, salud, esparcimiento etc.), así como de los servicios a las empresas (servicios financieros, asistencia jurídica, consultoría, publicidad, marketing, informática etc.) y el comando de las actividades asociadas a las nuevas tecnologías de la información y las comunicaciones (NTIC);

c) la parte más moderna y dinámica de la industria manufacturera, que desde la mitad de los años 80 recuperó su tendencia a localizarse preferentemente en esta parte del territorio, con lo que tanto el PIB regional como el industrial de la RMS lograron recuperar la participación que tenían en el período de auge del modelo sustitutivo (DE MATTOS, 1999), y

d) las actividades orientadas a un mercado interno metropolitano en progresiva reactivación, como consecuencia de la presencia en el AMS de una demanda diversificada y sofisticada, asociado a la localización y al crecimiento en este lugar de la nueva base económica metropolitana y, por tanto, de la mayor parte de los trabajos mejor remunerados del país.

Pese a su indudable profundidad, la ola modernizadora que impulsó esta transformación de la base económica metropolitana se produjo en forma relativamente rápida y, aún cuando alcanzó la mayor parte del territorio nacional, fue especialmente en el AMS donde tuvo su expresión más generalizada y amplia, dado que fue aquí donde se emplazó la mayoría de los eslabones de las RPTF. Este proceso fue acompañado por un igualmente rápido desarrollo de la infraestructura requerida para asegurar el funcionamiento globalizado de estas actividades (red telefónica digitalizada y de comunicaciones electrónicas, red de conexiones aéreas, aeropuerto internacional con el equipamiento requerido por las líneas aéreas internacionales, red de circuitos financieros con creciente incorporación de nuevos productos, incluida una red de cajeros automáticos bancarios de cobertura nacional etc.).

Al materializar este conjunto de transformaciones, esta aglomeración metropolitana inició su evolución hacia un tipo de ciudad cuyo rasgo medular es que "[...] se ha tornado en el lugar en el que las redes tendencialmente planetarias de variada naturaleza - de las redes técnicas de transportes y de comunicaciones a las empresasredes transnacionales, a las redes de las universidades y de la investigación, de las medias, del mercado financiero - concentran sus 'nodos' para realizar conexiones y sinergias recíprocas" (DEMATTEIS, 1998-1999, p. 2), lo que establece la diferencia medular con la ciudad de la época del fordismo: "las metrópolis modernas no son más sistemas autocentrados, sino poderosos entrecruzamientos de redes múltiples" (VELTZ, 1997, p. 61).

Mas allá de las diferencias que naturalmente tiene con las ciudades de los países desarrollados, en esta nueva dinámica Santiago fue adquiriendo, a su escala, la mayor parte de los rasgos que identifican a las ciudades que funcionan bajo la dinámica de la globalización en todas partes del mundo, adscribiéndose a la caracterización de Marcuse y Kempen (2000) para lo que denominan como una globalizing city; de esta manera, el AMS comenzó a funcionar como el principal lugar estratégico en Chile para las operaciones económicas globales (SASSEN, 1994). 
Así, a medida que Chile fue mejorando su posición en los rankings internacionales de competitividad, también Santiago poco a poco fue logrando ubicarse mejor en la red mundial de ciudades en vías de globalización, como lo muestra, por ejemplo, la clasificación realizada por la Globalization and World Cities Study Group and Network $(\mathrm{GaWC})$ de la Loughsborough University del Reino Unido, que la sitúa en un lugar destacado con relación a las restantes ciudades latinoamericanas consideradas (BEAVERSTOK, SMITH \& TAYLOR, 1999; FOSSAERT, 2001). Lo mismo ocurre en otros rankings de ciudades, como los realizados por la consultora internacional William Mercer o por las revistas Fortune o América Economía. En lo esencial, lo que estos antecedentes ponen en evidencia es la creciente articulación de esta ciudad en la red mundial de ciudades en globalización.

\section{II.3. Subsidiaridad estatal y nuevo enfoque para la gestión urbana}

En las mutaciones que comenzaron a producirse en el funcionamiento, la organización y la morfología de Santiago a lo largo de este proceso, incidió fuertemente el substancial cambio de enfoque de la gestión urbana que acompañó a la política de liberalización económica; en efecto, desde el momento en que comenzaron a producirse los cambios que impulsaron la reconfiguración del aparato productivo metropolitano y en que, con esa base se inició una nueva fase de crecimiento y expansión del AMS, el proceso respectivo estuvo regido por una concepción de gestión urbana compatible con el discurso teórico-ideológico que sustentaba esta fase de modernización capitalista, donde la subsidiaridad del Estado se ubicaba como principio rector. En lo esencial, este enfoque redefinió las reglas del juego a favor de aquellos actores sociales que tienen capacidad para llevar a cabo las intervenciones urbanas de mayor impacto que, en última instancia, son las que marcan la dirección de la transformación de la ciudad.

Ya desde El Ladrillo, documento que constituyó la base de la política económica del Gobierno Militar, se preconizaba la necesidad de implementar "un modelo de desarrollo basado en una economía descentralizada, en que las unidades productivas sean independientes y competitivas para aprovechar al máximo las ventajas que ofrece un sistema de mercado" (El Ladrillo, 1992, p.
62), donde "dentro del marco de la descentralización, la acción del Estado tiende a ser indirecta. [...]" (idem, p. 63). Estos principios fueron incorporados a la Política Nacional de Desarrollo Urbano sancionada por Gobierno Militar en 1979; en los documentos respectivos elaborados por el Ministerio de Vivienda y Urbanismo (MINVU), al mismo tiempo que se reafirmaba la importancia de consolidar el rol subsidiario del Estado, se establecía que "es el sector privado el principal encargado de materializar las iniciativas del desarrollo urbano que demanda la población, mediante la generación de una adecuada oferta de bienes y servicios" (MINVU, 1981a, p. 19). Así mismo, entre los principios básicos que cimentaban esta nueva política se precisaba que "el suelo urbano no es un recurso escaso", que "el uso del suelo queda definido por su mayor rentabilidad" (MINVU, 1981b, p. 11-12). Aún cuando las disposiciones ortodoxamente libre-mercadistas solamente alcanzaron a estar vigentes por un período relativamente breve, sus fundamentos teóricos se han mantenido hasta ahora como base de la gestión urbana en Chile.

En lo fundamental, este enfoque se propuso explícita y deliberadamente remover, debilitar o neutralizar las regulaciones contempladas por la concepción más intervencionista de planificación urbana que había dominado en la fase anterior. Tales regulaciones, habían pretendido - en la mayor parte de los casos infructuosamente controlar o regular el despliegue de "la multitud de procesos privados de apropiación de espacio" que, como afirma Topalov (1979, p. 20) caracterizan la dinámica de la urbanización capitalista. Con ello, en lo esencial, el nuevo enfoque contribuyó a mejorar las condiciones para la afirmación de una lógica estrictamente capitalista en la producción y reproducción metropolitana.

En consecuencia, desde entonces, se impuso una mayor libertad para la materialización de las preferencias locacionales de las empresas y de las familias, haciendo que sus estrategias, decisiones y acciones pasasen a jugar un papel aún más importante en el funcionamiento, la morfología y la imagen de la ciudad. En definitiva, esto puede interpretarse como que de esta forma se establecieron condiciones para el más adecuado funcionamiento en el Gran Santiago de lo que Molotch (1976) denominó y caracterizó como la "urban growth machine"; esto es, de una coalición 
de miembros de élites directa o indirectamente relacionadas con los negocios inmobiliarios, que buscan asegurar las precondiciones para el crecimiento de su ciudad y que conducen las correspondientes políticas urbanas con el propósito de expandir la economía local y acumular riqueza (JONAS \& WILSON, 1999).

Al reducirse las intervenciones e inversiones públicas bajo el imperio de un Estado subsidiario, la maximización de la plusvalia urbana se consolidó como el principal criterio urbanístico, con lo que la "máquina del crecimiento urbano" se encontró frente a condiciones más favorables para poder sobrepasar muchas de las regulaciones aún vigentes. En particular, desde el momento en que el capital inmobiliario, fuese cual fuese su procedencia, percibió que la reactivación económica del AMS la transformaba en el lugar de residencia de la parte más moderna y dinámica del aparato productivo nacional $\mathrm{y}$, consecuentemente, de las capas sociales receptoras de los más altos ingresos, el suelo metropolitano pasó a ser considerado como un medio privilegiado para la valorización de sus capitales, por lo que las inversiones tuvieron un significativo y sostenido aumento en este ámbito territorial. En la medida que las principales nuevas intervenciones urbanas resultaron fundamentalmente de iniciativas privadas motivadas por la ganancia esperada para cada una de ellas, el crecimiento de la ciudad se hizo mucho más fragmentario.

De esta manera, los negocios inmobiliarios articulados en forma dinámica con las preferencias de los principales actores urbanos pasaron a jugar un papel todavía más importante en el fortalecimiento de las tendencias a la expansión metropolitana. Además, bajo las condiciones generadas por la apertura externa y la globalización, se acentuó la influencia de dos factores en el desencadenamiento de la nueva dinámica urbana y, por lo tanto, en la configuración de la "otra ciudad":

a) el significativo crecimiento del número de vehículos motorizados y la generalización de su utilización en el transporte individual y colectivo, con un fuerte impacto en la reducción de la fricción de la distancia en las decisiones de localización de muchas familias y empresas y sin lo cual sería difícil explicar la tendencia a la metropolización expandida. Este fenómeno generó una demanda creciente por nuevas carreteras y autopistas, las cuales ganaron una creciente importancia como ejes para la expansión urbana, contribuyendo a afirmar una morfología urbana de tipo tentacular, $\mathrm{y}$

b) la adopción generalizada de las NTIC, que también contribuyó significativamente a reducir la importancia de la distancia en las decisiones sobre localización de las empresas y de las familias y estimuló el crecimiento del periurbano como lugar alternativo de residencia, así como también de localización de numerosas actividades productivas.

Bajo estas condiciones, diversos procesos productivos, así como también una parte importante de la población, dejaron de tener la necesidad de concentrarse en el área urbana contigua, aún cuando manteniendo siempre su preferencia por una razonable proximidad al lugar donde se situaba la mayor aglomeración de actividades y de población. En lo fundamental, en una situación caracterizada por la mayor presencia del transporte automotor y por la difusión generalizada de las NTIC, se produjo una significativa extensión del campo de externalidad metropolitano hacia un ámbito territorial cada vez más amplio, lo que constituye uno de los cambios fundamentales para explicar las nuevas tendencias expansivas metropolitanas; como destaca Dematteis (1998, p. 25), "actualmente los nuevos campos de externalidad no tienen ya una forma de área compacta, ni un radio tan limitado, sino que se configuran como retículas articuladas en centros y sistemas urbanos pequeños o grandes, en extensiones territoriales macrorregionales". Bajo esta dinámica, la difusión de la organización productiva en red redundó en la formación de un verdadero sistema productivo central, donde la metrópoli emergente aparece como el resultado de un proceso simultáneo de articulación entre distintos puntos del territorio a través de una intrincada red de flujos y de dispersión de las actividades y la población en un área cada vez más extensa (MENDEZ, 2001, p. 146).

En el caso del AMS, el respectivo sistema productivo central ha ido incorporando al espacio central de flujos a diversos centros urbanos situados en su proximidad, en un área de influencia de extensión regional. En suma, se puede afirmar que bajo el impacto de la liberalización económica y de la desregulación, se consolidaron en Santiago condiciones y factores análogos a aquellos que impulsaron e impulsan el sprawl en las grandes 
ciudades norteamericanas, por lo que también en esta ciudad comenzó a desplegarse una modalidad similar de expansión metropolitana. Podría afirmarse, como conclusión que sería este conjunto de condiciones y factores lo que produjo el cambio de referente urbano de Santiago, imponiendo en los hechos una tendencia que ha sido calificada como de "angelinización" (SARLO, 1994, p. 14ss), en la medida que parece replicar la que caracteriza la evolución de Los Angeles.

¿Cuáles serían los principales efectos de los cambios en la dinámica económico-productiva y en el enfoque de la gestión urbana sobre la organización y el funcionamiento metropolitano? En lo esencial, cabría destacar dos tipos de efectos, uno que incide sobre la configuración social de la ciudad y el otro sobre la morfología físico-territorial, efectos que si bien ya habían comenzado a manifestarse en la fase anterior, ahora presentan síntomas de incontrolable generalización:

a) una polarización social, que se expresa en una estructura urbana en la que la acentuación de las desigualdades y la segregación residencial tienen una clara lectura territorial, $\mathrm{y}$

b) una expansión metropolitana, que se manifiesta en una estructura policéntrica de dimensión regional, que se prolonga en todas las direcciones posibles a través de una periurbano difuso, de densidad decreciente, que no parece encontrar límites.

GRÁFICO 1 - Impactos metropolitanos de la globalización

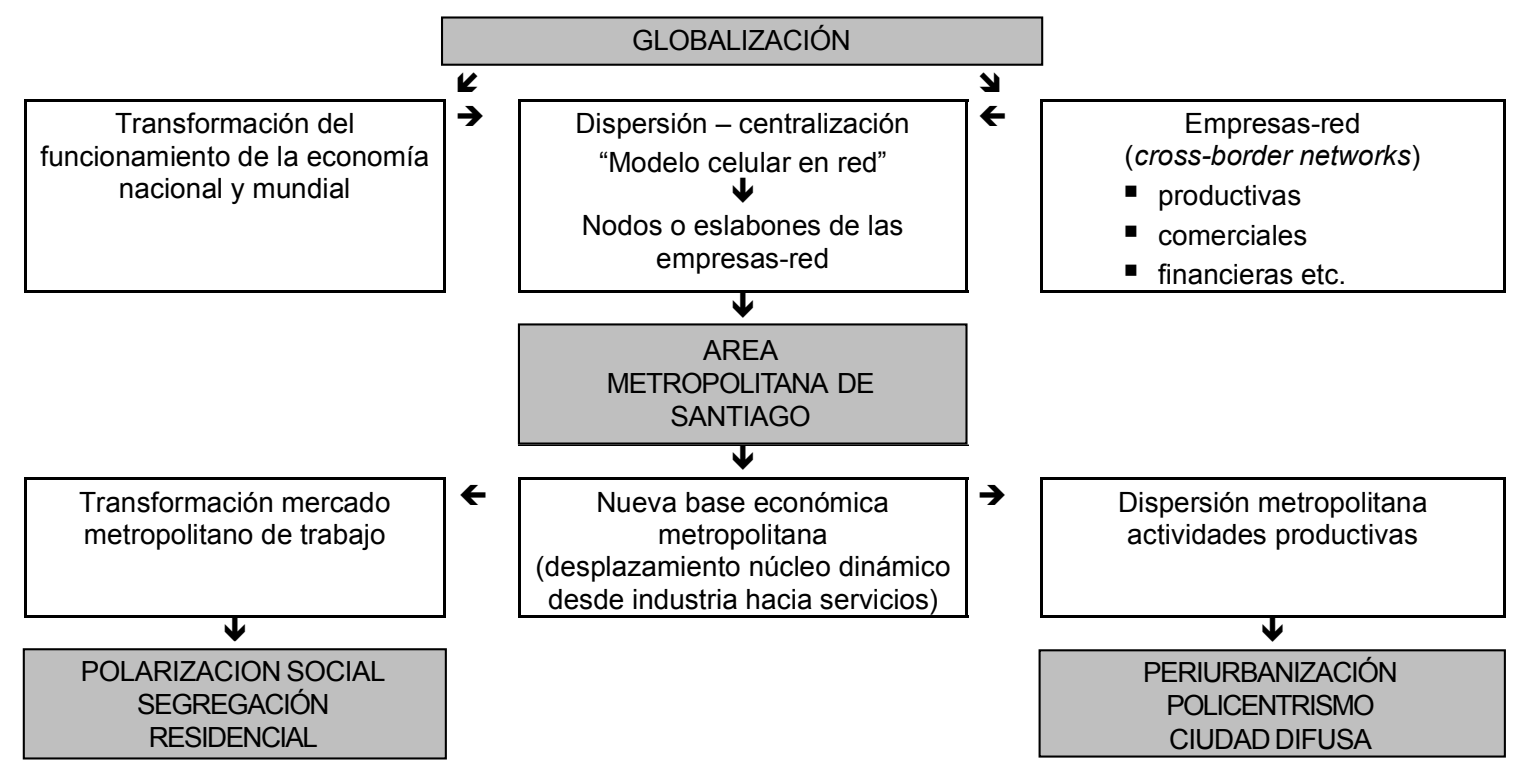

III. LA OTRA CIUDAD: POLARIZACIÓN SOCIAL Y SEGREGACIÓN RESIDENCIAL

En la medida que la estructura y la morfología de cada ciudad expresa los rasgos y las peculiaridades de la estructura del mercado de trabajo en torno al que se ha constituido y evolucionado $\mathrm{y}$, por lo tanto, de las segmentaciones y polarizaciones que le caracterizan, resulta fundamental observar cuales fueron los efectos de las transformaciones consideradas precedentemente sobre el mercado de trabajo del AMS.

Para analizar el caso del AMS, ante todo debe tenerse en cuenta que en este período los cambios y la evolución de su mercado laboral estuvieron encuadrados por la liberalización y flexibilización de la relación salarial, impulsada por el Código de Trabajo sancionado por el Gobierno Militar en 1979 y cuya vigencia se ha mantenido hasta ahora con muy ligeras modificaciones. Al respecto, importa destacar que esta reforma laboral estuvo orientada a desmantelar los arreglos institucionales establecidos en el período anterior, que eran considerados como obstáculos para el proceso de acumulación y crecimiento, y a sustituirlos por una mayor flexibilización de la relación salarial.

En el escenario que se fue configurando desde entonces, las elevadas tasas de crecimiento 
económico del período 1985-1998 tuvieron importantes efectos en la evolución del empleo y de la estructura ocupacional. Es así que durante el período 1986-1996 (OIT, 1998) se produjo la creación neta de más de 1400000 empleos, lo que estuvo asociado a una fuerte baja de la tasa de desocupación, desde 10,4\% en 1986 hasta 5,4\% en 1996. Por otra parte, al mismo tiempo se registró un significativo aumento del ingreso por habitante, que ascendió de US\$1 360 en 1985 a US\$ 5050 en 1996.

En cualquier caso, pese a esta mejoría general y no obstante el elevado crecimiento económico registrado y la intensificación de las políticas sociales, las cifras para este período documentan la persistencia de una situación de aguda polarización social, así como la aparición de síntomas de mayor segmentación y precarización del mercado de trabajo. La mayor parte de los estudios sobre el tema reconocen que las desigualdades sociales heredadas no se modificaron sustancialmente (Cuadro 2), por lo que Chile continúa ubicado entre los países latinoamericanos con una más regresiva distribución del ingreso (VALDES, 1999, p. 10-11).

CUADRO 2 - Distribución del ingreso autónomo de los hogares, por decil del ingreso autónomo per cápita del hogar4 (Chile, 1990-1998)

\begin{tabular}{|c|c|c|c|c|c|c|c|c|c|c|c|c|}
\hline Decil $^{5}$ & $\mathbf{1}$ & $\mathbf{2}$ & $\mathbf{3}$ & $\mathbf{4}$ & $\mathbf{5}$ & $\mathbf{6}$ & $\mathbf{7}$ & $\mathbf{8}$ & $\mathbf{9}$ & $\mathbf{1 0}$ & Total & $\begin{array}{c}\mathbf{9 + 1 0 /} \\
\mathbf{1 + 2}\end{array}$ \\
\hline 1990 & 1,4 & 2,7 & 3,6 & 4,5 & 5,4 & 6,9 & 7,8 & 10,3 & 15,2 & 42,2 & 100,0 & 14,0 \\
\hline 1992 & 1,5 & 2,8 & 3,7 & 4,6 & 5,6 & 6,6 & 8,1 & 10,4 & 14,8 & 41,9 & 100,0 & 13,2 \\
\hline 1994 & 1,3 & 2,7 & 3,5 & 4,6 & 5,5 & 6,4 & 8,1 & 10,6 & 15,4 & 41,9 & 100,0 & 14,3 \\
\hline 1996 & 1,3 & 2,6 & 3,5 & 4,5 & 5,4 & 6,3 & 8,2 & 11,1 & 15,5 & 41,6 & 100,0 & 14,6 \\
\hline $1998^{6}$ & 1,2 & 2,5 & 3,5 & 4,5 & 5,3 & 6.4 & 8,3 & 11,0 & 16,0 & 41,3 & 100,0 & 15,5 \\
\hline
\end{tabular}

Fuente: Encuestas de Caracterización Socio-económica (CASEN), del MIDEPLAN (1999).

¿Qué efectos tuvo el crecimiento registrado en este período sobre la estructura social metropolitana? El hecho más relevante es que, de igual forma a como ocurrió a escala nacional, los niveles de pobreza y de indigencia disminuyeron de manera significativa en la RMS durante el período 1990-1998: la pobreza se redujo desde $38,6 \%$ hasta $15,4 \%$ de la población respectiva, mientras que la indigencia descendió de 9,6\% a 3,5\% (MIDEPLAN, 1999). Además, en razón del fuerte crecimiento registrado entre 1985 y 1998 y de los efectos de las políticas sociales aplicadas desde 1990, en este período todos los indicadores muestran un sustantivo crecimiento del ingreso

\footnotetext{
4 Se excluye al servicio doméstico puertas adentro y su núcleo familiar.

5 Deciles construidos a partir del ingreso autónomo per cápita del hogar.

6 Cifras preliminares.
}

real mensual por familia y por habitante, así como de los gastos de las familias y de las personas (INE, 1999).

Asimismo, los índices de pobreza en la RMS son más débiles que los de otras regiones del país: $14,8 \%$ en 1996 en comparación, por ejemplo, con $36,5 \%, 33,9 \%$ y $32,5 \%$ que corresponden respectivamente a las regiones IX (Araucanía), VIII (Bio Bio) y VII (Maule). Sin embargo, si se compara la polarización de los ingresos entre el $20 \%$ más rico y el $20 \%$ más pobre de la población de cada región, se puede comprobar que la correspondiente a la RMS es una de las más contrastadas del país (Cuadro 3).

La regresiva distribución del ingreso se refleja en una distribución de la población de Santiago que ha ido dibujando un mapa donde la segregación residencial tiene una nítida expresión territorial (RODRÍGUEZ \& WINCHESTER, 2001). Este fenómeno de segregación, que tiene orígenes lejanos, tendió a acentuarse aún más con las 
CUADRO 3 - Distribución ingreso monetario promedio mensual de hogares - porcentaje del ingreso total regional por quintiles (Chile, 1996)

\begin{tabular}{|l|c|c|c|c|c|c|}
\hline \multirow{2}{*}{ Región } & \multicolumn{5}{|c|}{ Quintiles } & 20\% más rico/ \\
\cline { 2 - 6 } & $\mathbf{I}$ & $\mathbf{I I}$ & III & IV más pobre & V & \\
\hline Tarapacá & 4,8 & 9,6 & 14,9 & 21,5 & 49,2 & 10,3 \\
\hline Antofagasta & 5,3 & 10,5 & 15,5 & 21,7 & 47,0 & 8,9 \\
\hline Atacama & 4,1 & 8,0 & 11,6 & 17,6 & 58,8 & 14,3 \\
\hline Coquimbo & 5,1 & 9,9 & 13,3 & 18,4 & 53,3 & 10,5 \\
\hline Valparaíso & 5,4 & 10,3 & 13,4 & 21,8 & 49,1 & 9,1 \\
\hline O'Higgins & 4,8 & 9,6 & 13,5 & 18,9 & 53,2 & 11,1 \\
\hline Maule & 4,7 & 9,0 & 13,3 & 17,9 & 55,1 & 11,7 \\
\hline Bío Bío & 4,2 & 8,1 & 11,8 & 18,5 & 57,5 & 13,6 \\
\hline Araucanía & 4,4 & 8,9 & 13,2 & 18,5 & 55,0 & 12,5 \\
\hline Los Lagos & 5,0 & 8,5 & 12,9 & 17,7 & 55,8 & 11,2 \\
\hline Aisén & 5,3 & 9,8 & 14,8 & 20,9 & 49,2 & 9,3 \\
\hline Magallanes & 5,4 & 10,3 & 14,0 & 20,5 & 49,8 & 9,2 \\
\hline Metropolitana & 4,3 & 8,0 & 11,6 & 18,8 & 57,3 & 13,3 \\
\hline
\end{tabular}

Fuente: elaboración propia, en base a MIDEPLAN (1999).

erradicaciones llevadas a cabo por el régimen militar, por las cuales se desplazó a importantes contingentes de población de bajos ingresos localizada hasta entonces en algunos barrios ricos, para reinstalarlos en áreas más pobres de la periferia del AMS.

En este sentido, los resultados de la Encuesta CASEN de 1998 muestra como se ha ido estableciendo la distribución territorial de la población por comunas según su nivel de ingreso: mientras los niveles de pobreza eran respectivamente de $0,8 \%, 1,1 \%$ y $1,2 \%$ en las 3 comunas más ricas del AMS (Providencia, Las Condes y Vitacura), en las 3 comunas más pobres (Huechuraba, Renca y Pedro Aguirre Cerda) los niveles de población por debajo de la línea de pobreza alcanzaban al $38,4 \%, 37,1 \%$ y $32,7 \%$.

En la misma dirección, el cálculo de un Índice de Desarrollo Humano (IDH) por comunas para el caso de Chile (PNUD-MIDEPLAN, 1999; 2000) permite una mejor aproximación a la forma en que se distribuye territorialmente la población metropolitana a través de un indicador más amplio que el de niveles de pobreza, por cuanto considera además la situación en salud, educación e ingresos (Cuadro 4). De esta manera, se puede comprobar que los sectores que tienen un IDH más elevado tienden a residir predominantemente en un cono que tiene su vértice en la Comuna de Santiago y que se va abriendo hacia el nor-oriente, abarcando las comunas de Vitacura, Providencia, Las Condes, Lo Barnechea, a las que se podrían agregar las comunas de La Reina, Ñuñoa y La Florida, habitadas principalmente por sectores de clase media (Mapa 1). Por otra parte, al poniente de una línea imaginaria que cruza la ciudad de norte a sur a la altura de la Comuna de Santiago se despliega un conjunto de comunas donde se distribuyen los sectores de menores ingresos, donde se puede apreciar que niveles extremadamente bajos del IDH se concentran en dos comunas de la periferia del AMS (Cerro Navia y Lo Espejo). 
CUADRO 4 - Índice de Desarrollo Humano en el AMS - diferencias por comuna

\begin{tabular}{|c|c|c|c|c|}
\hline $\begin{array}{c}\text { Bajo } \\
0,65 \text { a } 0,699\end{array}$ & $\begin{array}{c}\text { Medio-bajo } \\
0,7 \text { a } 0,749\end{array}$ & $\begin{array}{c}\text { Medio } \\
0,75 \text { a } 799\end{array}$ & $\begin{array}{c}\text { Alto } \\
0,8 \text { a } 0,899\end{array}$ & $\begin{array}{c}\text { Muy alto } \\
0,9 \text { a } 1\end{array}$ \\
\hline $\begin{array}{l}\text { Cerro Navia } \\
\text { Lo Espejo }\end{array}$ & $\begin{array}{l}\text { Peñalolén } \\
\text { San Joaquín } \\
\text { Est. Central } \\
\text { Recoleta } \\
\text { San Bernardo } \\
\text { Conchalí } \\
\text { Quinta Normal } \\
\text { La Granja } \\
\text { Independencia } \\
\text { Talagante } \\
\text { Pudahuel } \\
\text { El Bosque } \\
\text { Pedro A. Cerda } \\
\text { Padre Hurtado } \\
\text { Huechuraba } \\
\text { Quilicura } \\
\text { San Ramón } \\
\text { Renca } \\
\text { La Pintana }\end{array}$ & $\begin{array}{l}\text { La Cisterna } \\
\text { Macul } \\
\text { San Miguel } \\
\text { Maipú } \\
\text { Cerrillos } \\
\text { Puente Alto }\end{array}$ & $\begin{array}{l}\text { Las Condes } \\
\text { Lo Barnechea } \\
\text { La Reina } \\
\text { Ñuñoa } \\
\text { Santiago } \\
\text { La Florida }\end{array}$ & $\begin{array}{l}\text { Vitacura } \\
\text { Providencia }\end{array}$ \\
\hline
\end{tabular}

Fuente: PNUD-MIDEPLAN (2000).

MAPA 1 - Índice de Desarrollo Humano del Gran Santiago

\section{Indice Desarrollo Humano}

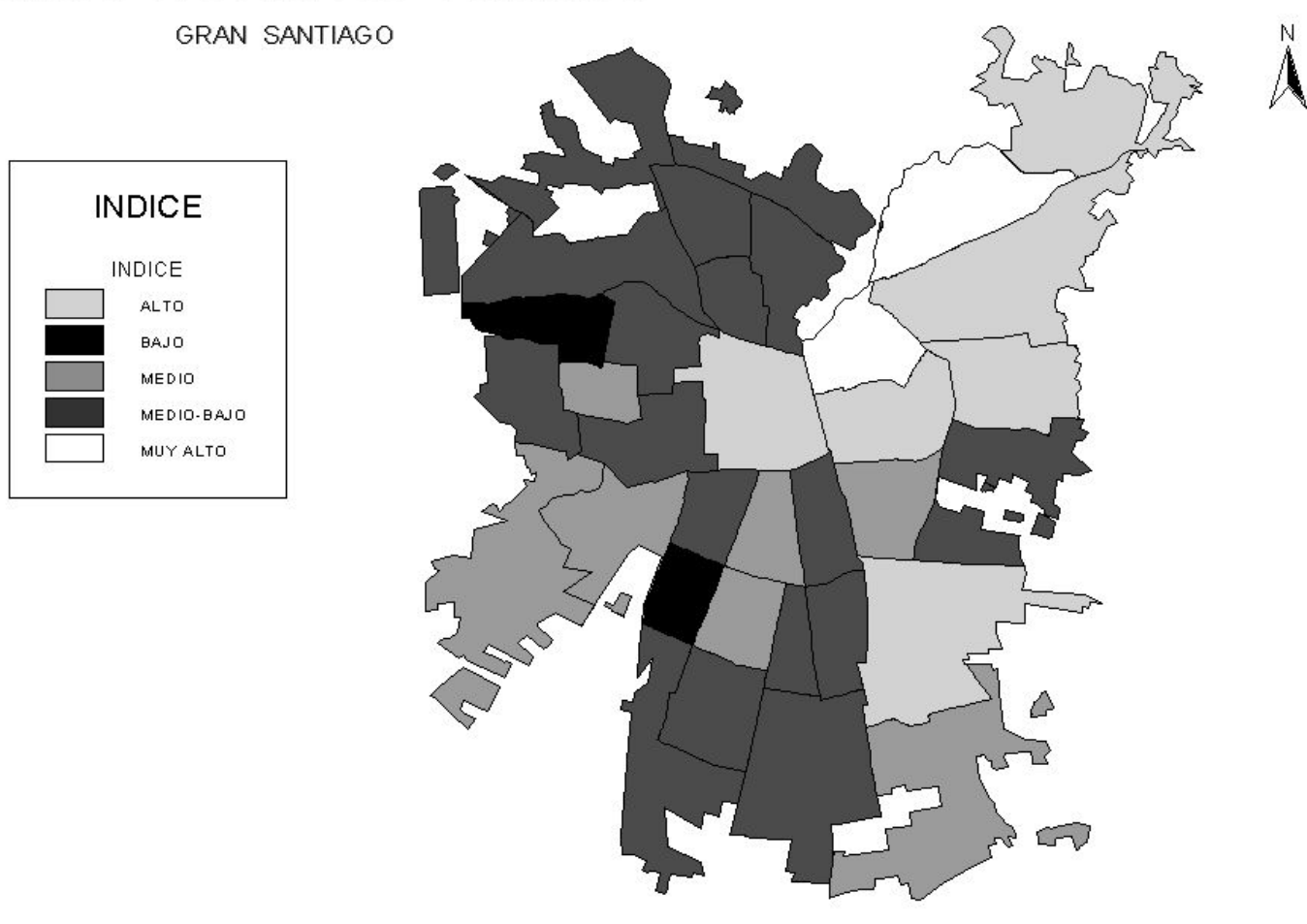

FONTE: Rodríguez Vignoli (1993) y Ducci, De Mattos y Gonzalez (2002). 
La persistencia de la polarización y de la segregación residencial, agravada por una acentuada desocupación juvenil en las comunas más pobres de la ciudad, ha tenido una importante incidencia en un aumento de los fenómenos relacionados con el consumo y la comercialización de la droga, con el crecimiento de la delincuencia y con la agudización de cierto tipo de conflictividad social, que se expresa en todo tipo de manifestación callejera y, especialmente, en los espectáculos deportivos masivos. Todos estos fenómenos están teniendo una creciente influencia tanto en la organización de la vida urbana como en la apariencia de la metrópoli que, en muchos de sus barrios, se muestra como una ciudad asediada, temerosa y vigilada y que está dando lugar a la aparición de recintos cerrados y protegidos en diversas zonas residenciales. El agravamiento de problemas de esta naturaleza está configurando una agenda para la gestión urbana frente a la cual los gobiernos comunales, en un cuadro de creciente liberalización y desregulación, no disponen de instrumentos efectivos para hacerles frente.

\section{LA OTRA CIUDAD: METROPOLIZACIÓN EXTENDIDA, POLICENTRISMO, PE- RIURBANIZACIÓN}

El AMS ya había experimentado una fuerte expansión territorial durante los años de mayor auge de la industrialización sustitutiva de importaciones, pues fue especialmente en las décadas de los años 1950 y 1960, cuando el desborde de su mancha urbana alcanzó mayor impulso (Cuadro 5); esto ocurrió fundamentalmente como consecuencia de un fuerte desplazamiento de población rural hacia esta ciudad, al mismo tiempo que la industria sustitutiva mostraba una marcada propensión a concentrarse en la proximidad del mercado interno de mayor dimensión, esto es, del que se había conformado en torno al Gran Santiago.

CUADRO 5 - Tasas crecimiento superficie y población AMS

\begin{tabular}{|c|c|c|}
\hline Anos & $\begin{array}{c}\text { Tasa media } \\
\text { crecimiento } \\
\text { superficie AMS }\end{array}$ & $\begin{array}{c}\text { Tasa media } \\
\text { crecimiento } \\
\text { población AMS }\end{array}$ \\
\hline $1940-1952$ & $2,8^{\mathrm{a}}$ & $3,1^{\mathrm{c}}$ \\
\hline $1952-1960$ & $4,1^{\mathrm{a}}$ & $4,1^{\mathrm{c}}$ \\
\hline $1960-1970$ & $4,2^{\mathrm{a}}$ & $3,1^{\mathrm{c}}$ \\
\hline $1970-1982$ & $2,4^{\mathrm{a}}$ & $2,7^{\mathrm{a}}$ \\
\hline $1982-1992$ & $1,6^{\mathrm{a}}$ & $1,9^{\mathrm{a}}$ \\
\hline $1991-2000$ & $2,5^{\mathrm{b}}$ & $1,3^{\mathrm{a}}$ \\
\hline
\end{tabular}

Fuente: a) calculado a partir cifras INE (s/d; 1987; 1995; 2002); b) calculado base datos investigación DIPUC (apud DUCCI, DE MATTOS \& GONZALEZ, 2002); c) Rodríguez Vignoli (1993).

Así, al culminar la fase industrial-desarrollista ya era evidente la preocupación por la progresiva concentración de un porcentaje mayoritario y creciente del PIB y de la población en la Región Central de Chile: "el alto grado de primacía y el rápido crecimiento relativo de la Región Central comparada con el resto del país corresponde casi exclusivamente a la primacía y desarrollo de la ciudad de Santiago" (CIDU, 1972, p. 10). Casi dos décadas más tarde, un estudio sobre la Región Capital confirmaba la continuidad de esta evolución y subrayaba que "Santiago concentra más del $60 \%$ de las actividades económicas del país, $40 \%$ de la población y de la fuerza de trabajo nacional, y sobre el $80 \%$ del movimiento financiero [...]"
(MINGO, CONTRERAS \& ROSS, 1990, p. 8). Entonces ya se vislumbraba la tendencia hacia la formación de una ciudad-región, a la que su propia dinámica expansiva terminaría por anexar a algunos centros urbanos aledaños que hasta ese momento habían funcionado en forma relativamente independiente (San Bernardo, Maipú, Puente Alto, Quilicura, Lo Barnechea), al mismo tiempo que articularía al funcionamiento metropolitano cotidiano a otros bajo la modalidad de ciudades satélites y/o ciudades dormitorio (Rancagua, Melipilla, Talagante, Colina).

Con esta evolución como antecedente, al transformarse durante las últimas décadas la base económica de la ciudad bajo los efectos de la 
globalización y comenzar a operar una modalidad de gestión urbana basada en la liberalización y la desregulación, la expansión metropolitana logró un nuevo impulso, pero ahora materializándose en una organización y en una morfología más compleja que la que había comenzado a esbozarse en la fase precedente. Más allá de sus diferencias con las ciudades de los países desarrollados, Santiago comenzó a vivir un proceso de transformación que, en términos generales, sigue la misma dirección señalada por Ascher (1995, p. 19) para el caso de los países de urbanización más antigua: "la metropolización opera más por una dilatación de las principales zonas urbanas, y por la integración al funcionamiento metropolitano (migraciones alternantes y relaciones económicas cotidianas al interior de un mismo espacio metropolitano) de ciudades periféricas, aún del conjunto de una región". Y, además, donde también "la pérdida eventual de población de sus ciudades centros, interpretado erróneamente como la declinación de las grandes ciudades, no es en nada contrario a la metropolización, pero expresa más bien la recomposición funcional y social de los espacios metropolitanos" (ibidem).

En el caso de Santiago los síntomas de la transformación hacia una ciudad en continua dilatación pueden ser percibidos en varios fenómenos y tendencias que comienzan a manifestarse como rasgos de esa "otra ciudad" en formación, habida cuenta siempre de ciertas peculiaridades inherentes a su pertenencia a una economía emergente:

a) pérdida de población de las áreas centrales, en beneficio de un mayor crecimiento periurbano, donde destaca el de las comunas del borde de la mancha urbana;

b) mayor crecimiento relativo de la mayoría de las provincias y de los centros urbanos que rodean al AMS;

c) creciente policentralización de la estructura, de la organización y del funcionamiento metro- politano;

d) aparición de áreas intersticiales configuradas como un espacio híbrido, ni estrictamente urbano, ni estrictamente rural, $\mathrm{y}$

e) proliferación de nuevos artefactos urbanos de gran capacidad estructurante.

IV.1. Pérdida de población del núcleo central y crecimiento de los bordes

Cuando se analizan los cambios que han afectado exclusivamente a la mancha urbana central del Gran Santiago durante los últimos 20 años se comprueba que mientras las comunas centrales perdieron población o ralentizaron su crecimiento, las comunas periurbanas crecieron en forma persistente. Así, durante el período 19821992 esto ocurrió en la mayoría de las comunas más importantes del núcleo histórico de la ciudad (Santiago, Estación Central, Independencia, La Cisterna, Ñuñoa, Pedro Aguirre Cerda, Providencia, Quinta Normal, Recoleta, San Joaquín y San Miguel), en tanto que varias de las comunas del borde urbano crecieron a una tasa promedio anual muy elevada: La Florida: 5,55\%; La Pintana: 7,31\%; Lo Barnechea: 6,95\%; Maipú: 8,14\%; Puente Alto: 8,10\%; Quilicura: 5,87\%; San Bernardo: 3,79\% (RODRIGUEZ VIGNOLI, 1993).

Esta tendencia se mantuvo y acentuó en el período 1992-2002, cuando de las 22 comunas del área central de la ciudad solamente dos (Providencia y Renca) aumentaron ligeramente su población, mientras las 20 restantes registraron pérdidas, en algunos casos significativos (Cuadro 6). Mientras tanto, ganaron población las 13 comunas que forman el periurbano inmediato del Gran Santiago, algunas de ellas con una variación porcentual intercensal sumamente elevada, como es el caso de Quilicura (207,7\%), Puente Alto (96,7\%), Maipú (80,7\%), Lo Barnechea (44,5\%) y Pudahuel (40,9\%). Estas tendencias ilustran sobre la fuerza que ha adquirido el proceso de metropolización expandida. 
CUADRO 6 - Crecimiento de las comunas - área central y comunas periurbanas (1992-2002)

\begin{tabular}{|c|c|c|c|}
\hline \multicolumn{2}{|c|}{ Comunas área central } & \multicolumn{2}{|c|}{ Comunas periurbanas } \\
\hline Comunas & $\begin{array}{c}\text { Variación } \\
1992-2002(\%)\end{array}$ & Comunas & $\begin{array}{c}\text { Variación } \\
1992-2002(\%)\end{array}$ \\
\hline Santiago & $-10,8$ & Borde Norte & \\
\hline Cerrillos & $-0,8$ & Huechuraba & 19,9 \\
\hline Cerro Navia & $-4,2$ & Quilicura & 207,7 \\
\hline Conchalí & $-12,5$ & & \\
\hline El Bosque & $-0,2$ & Borde Poniente & \\
\hline Estación Central & $-7,0$ & Pudahuel & 40,9 \\
\hline Independencia & $-16,4$ & Maipú & 80,7 \\
\hline La Cisterna & $-10,2$ & Padre Hurtado & 28,0 \\
\hline La Granja & $-0,1$ & & \\
\hline Lo Espejo & $-6,5$ & Borde Sur & \\
\hline Lo Prado & $-6,6$ & San Bernardo & 28,0 \\
\hline Macul & $-7,6$ & La Pintana & 14,9 \\
\hline Ñuñoa & $-6,3$ & Puente Alto & 96,7 \\
\hline Pedro Aguirre Cerda & $-12,9$ & & \\
\hline Providencia & 7,8 & Borde Oriente & \\
\hline Quinta Normal & $-10,4$ & Lo Barnechea & 44,5 \\
\hline Recoleta & $-14,7$ & Las Condes & 17,5 \\
\hline Renca & 0,6 & La Reina & 5,4 \\
\hline San Joaquín & $-13,9$ & Peñalolén & 20,4 \\
\hline San Miguel & $-5,3$ & La Florida & 11,0 \\
\hline San Ramón & $-5,7$ & & \\
\hline Vitacura & $-2,9$ & & \\
\hline
\end{tabular}

Fuente: Elaboración propia, con información INE (2002).

En cualquier caso, importa destacar que el crecimiento de las comunas del borde no se debe solamente al aumento de la población, sino también, y especialmente, a un incremento de las migraciones al interior de la ciudad ${ }^{7}$. En este sentido, una reciente investigación realizada en la Universidad de Chile comprobó que entre 1987 y 1992 se registraron 855 mil cambios de comuna y que "los espacios de la periferia de la ciudad

\footnotetext{
${ }^{7}$ Este fenómeno es análogo al observado en Estados Unidos, para el que un estudio reciente (KOLANKIEWICZ \&BECK, 2001) comprobó que el sprawl de sus 100 principales áreas urbanizadas puede ser explicado por mitades, por una parte, por el uso y consumo de tierra que conduce a un aumento del promedio de la cantidad de tierra urbana por habitante y, por otra parte, por el aumento del número de habitantes en esas 100 áreas urbanizadas.
}

alcanzan los niveles más altos de concentración de migrantes intraurbanos" (U_noticias, 2002). Este fenómeno debe ser analizado en relación al hecho de que el crecimiento de la población metropolitana se ha ido haciendo más lento debido, por una parte, a que con un nivel de urbanización que hoy supera el $86 \%$, hay una fuerte disminución de las migraciones rural-urbanas y, por otra parte, a que se ha comprobado "una tendencia descendente del crecimiento de la población del Gran Santiago, que se explicaría en virtud de una disminución de la tasa bruta de natalidad más intensa que la reducción de la tasa bruta de mortalidad" (RODRIGUEZ VIGNOLI, 1993, p. 44). En esta situación, ya no parece posible esperar tasas de crecimiento de la población metropolitana de la magnitud de las que se observaron en la fase culminante de la 
industrialización sustitutiva en las décadas de los años 1950 y 1960 cuando llegaron a valores superiores al $4 \%$ anual (Cuadro 5, supra) y cuando las migraciones rural-urbanas alcanzaron su máxima expresión y la tasa de crecimiento de la población era mucho más elevada.

En todo caso, las migraciones intrametropolitanas, según las cuales una parte considerable de la población desplaza su lugar de residencia hacia las comunas del borde, intensificando la redistribución de la población al interior del espacio metropolitano, igual contribuyen a mantener la dinámica expansiva de la mancha urbana principal. Esta tendencia, que en parte importante está motivada por la preferencia de las familias por la vivienda unifamiliar, asegura la continuidad de la metropolización expandida; la persistencia de este fenómeno, significa que aún con una disminución de la población, o con un crecimiento muy bajo, la mancha urbana podría seguir ampliándose, tal como Geddes (1997) ha mostrado para el caso de las ciudades norteamericanas.

Según un estudio basado en la comparación de las imágenes satelitales del AMS para los años 1991 y 2000, en este período el área de la superficie urbana contigua de la misma creció 12 016,4 hectáreas (DUCCI, DE MATTOS \& GONZALEZ, 2002), crecimiento que se situó en un anillo irregular en casi todo el perímetro del AMS. Esto significa que el área de Santiago se expandió en $24 \%$ en un lapso de algo menos de 10 años, alcanzando una superficie total de 62177 hectáreas, sin considerar el crecimiento experimentado por el periurbano no contiguo que, como veremos, también lo hizo en forma significativa. Si se compara la tasa de crecimiento anual correspondiente a esta expansión con las calculadas por el Instituto Nacional de Estadísticas (INE) para los distintos períodos intercensales ${ }^{8}$, es posible inferir que nuevamente la tasa de crecimiento de la superficie de la unidad urbana estaría superando a la tasa de crecimiento de la población (Cuadro 5, supra, y Gráfico 2).

GRAFICO 2 - Evolución de las tasas de crecimiento anual de la población y superficie AMS

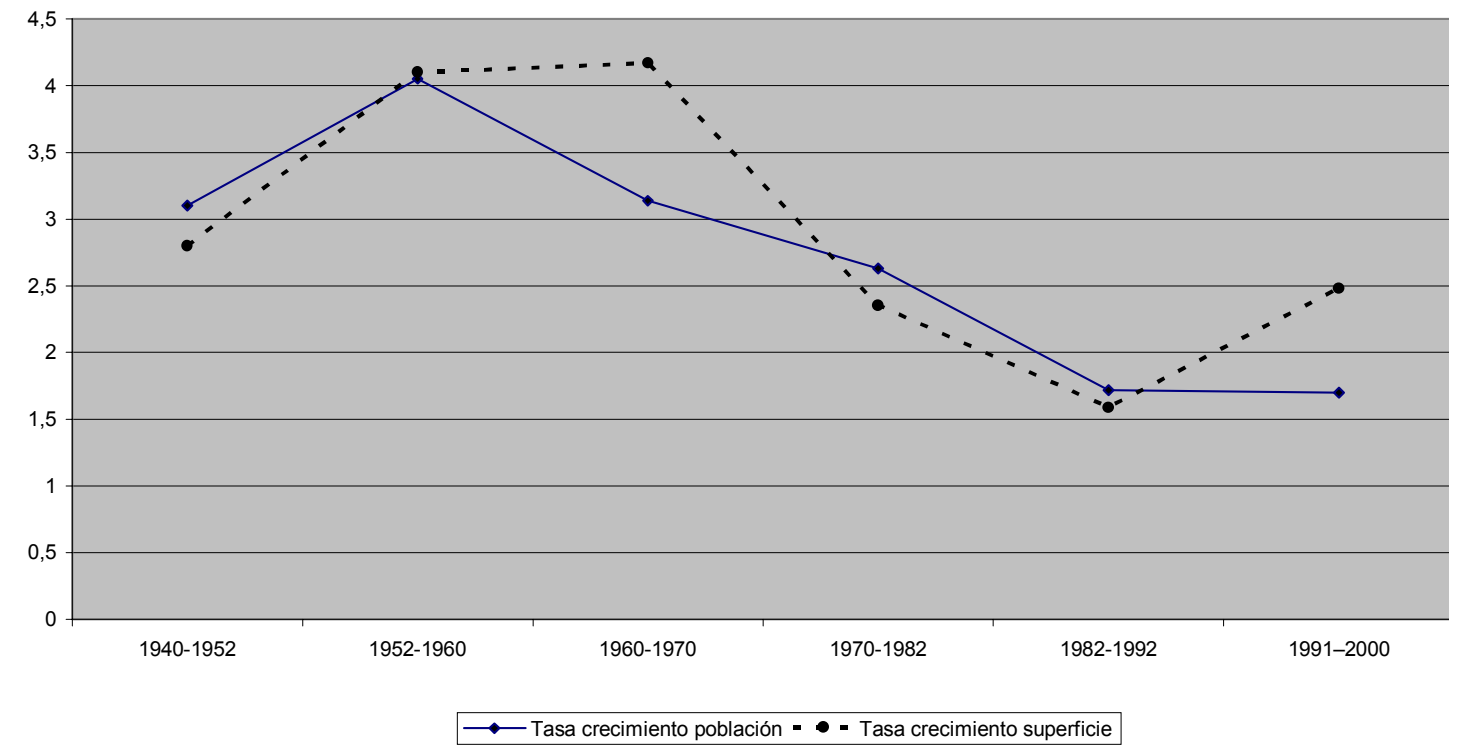

FONTE: Rodríguez Vignoli (1993) y Ducci, De Mattos y Gonzalez (2002).

\section{IV.2. Mayor crecimiento de provincias y centros periurbanos}

La información sobre el crecimiento de la población al interior de la RMS en los dos últimos períodos intercensales, permite identificar otra faceta del proceso de expansión periurbana: la que afecta a las áreas no conurbadas al exterior inmediato de la unidad urbana. Así, mientras en el período 1982-1992 la Provincia de Santiago, núcleo originario de la ciudad y componente principal de la misma, donde se ubican 32 de las 35 comunas que actualmente forman el AMS,

\footnotetext{
8 Aún cuando la metodología utilizada por el INE es diferente a la de este estudio, en términos generales esta comparación resulta válida para el análisis de tendencias.
} 
mostró una variación del orden de 16,3\% ligeramente menor al $17,8 \%$ de Chile, dos de las cinco provincias adyacentes incrementaron su población con la mayor variación de todo el país (Cordillera, $109,7 \%$ y Chacabuco, 58,9\%) en tanto que las tres restantes también tuvieron una variación muy superior al promedio nacional (Maipo 39,6, Talagante 23,9 y Malipilla 23,6). Este fenómeno se mantuvo en el período intercensal
1992-2002; la variación de la Provincia de Santiago cayó al 8,2\%, en tanto las provincias de Cordillera y de Chacabuco, que continúan siendo las de mayor crecimiento de todo el país, alcanzaron $91,1 \%$ y $46,0 \%$ respectivamente, en tanto que las tres restantes provincias de la RMS continúan teniendo un crecimiento muy superior al del país en su conjunto (Cuadro 7).

CUADRO 7 - Crecimiento provincias y comunas Gran Santiago (1982-2002)

\begin{tabular}{|c|c|c|c|c|c|}
\hline PROVÍNCIA Comuna & $\begin{array}{c}\text { Población } \\
\text { (1982) }\end{array}$ & $\begin{array}{l}\text { Población } \\
\text { (1992) }\end{array}$ & $\begin{array}{l}\text { Población } \\
(2002)\end{array}$ & $\begin{array}{c}\text { Variación } \\
(1982-1992- \\
\%)\end{array}$ & $\begin{array}{c}\text { Variación } \\
(1992-2002- \\
\%)\end{array}$ \\
\hline CHILE & 11329736 & 13348401 & 15050341 & 17,8 & 12,8 \\
\hline RMS (52 comunas) & 4318097 & 5257937 & 6038974 & 21,7 & 14,9 \\
\hline $\begin{array}{l}\text { SANTIAGO (32 } \\
\text { comunas) }\end{array}$ & 3694939 & 4295593 & 4647444 & 16,3 & 8,2 \\
\hline CHACABUCO & 57022 & 90640 & 132324 & 58,9 & 46,0 \\
\hline Colina & 28776 & 52769 & 77647 & 82,5 & 47,1 \\
\hline Lampa & 17834 & 25033 & 40098 & 38,8 & 60,2 \\
\hline Til-Til & 10412 & 12838 & 14579 & 21,8 & 13,6 \\
\hline TALAGANTE & 130279 & 166654 & 214215 & 23,9 & 28,5 \\
\hline Talagante & 32193 & 44908 & 59383 & 35,9 & 32,2 \\
\hline El Monte & 17201 & 21882 & 25758 & 24,1 & 17,7 \\
\hline Isla de Maipo & 18712 & 20344 & 24897 & 5,4 & 22,4 \\
\hline Padre Hurtado & & 29333 & 37543 & - & 28,0 \\
\hline Peñaflor & 62167 & 50187 & 66634 & 23,2 & 32,8 \\
\hline MELIPILLA & 95708 & 118802 & 139267 & 23,6 & 17,2 \\
\hline Melipilla & 64267 & 80255 & 92991 & 24,6 & 15,9 \\
\hline Alhué & 7329 & 4013 & 4414 & $-46,2$ & 10,0 \\
\hline Curacaví & 14329 & 19053 & 24146 & 31,5 & 26,7 \\
\hline María Pinto & 3415 & 8735 & 10211 & 155,7 & 16,9 \\
\hline San Pedro & 6328 & 6746 & 7505 & 4,7 & 11,3 \\
\hline CORDILLERA & 132275 & 277687 & 530718 & 109,7 & 91,1 \\
\hline Puente Alto & 113211 & 254673 & 501042 & 124,8 & 96,7 \\
\hline San José Maipo & 2731 & 11646 & 13188 & 323,43 & 13,2 \\
\hline Pirque & 16333 & 11368 & 16488 & $-30,8$ & 45,0 \\
\hline MAIPO & 207874 & 293021 & 375006 & 39,6 & 28,0 \\
\hline San Bernardo & 129127 & 190857 & 244354 & 46,0 & 28,0 \\
\hline Buin & 8936 & 52792 & 62851 & 487,23 & 19,1 \\
\hline Calera de Tango & 28021 & 11843 & 17996 & $-58,2$ & 52,0 \\
\hline Paine & 41790 & 37529 & 49805 & $-10,5$ & 32,7 \\
\hline
\end{tabular}

Fuentes: datos 1982: INE (1987); datos 1992 y 2002: INE (2002).

Este mayor crecimiento periurbano concierne especialmente a la mayoría de los centros urbanos ubicados en esas provincias circundantes del AMS, que tienen una relación funcional con el Gran Santiago y que aún no han sido absorbidos por la mancha urbana en expansión; en efecto, para el período 1982-1992 estos centros con muy pocas excepciones muestran una tasa de crecimiento anual muy superior a la del país en su conjunto y a la del AMS, así como también a la de la mayor parte de los centros de más de 100000 habitantes (MARTINEZ PIZZARRO, 1997). Si se observa en particular la evolución de los centros de más de 2500 habitantes que se encuentran ubicados dentro de un radio de 60 kilómetros desde el centro del AMS, se comprueba que entre 1982 y 1992 casi todos ellos mostraron una tasa de crecimiento mucho más elevada que el promedio nacional ${ }^{9}$ (Cuadro 6, supra).

\footnotetext{
9 Aún cuando todavía no se dispone de la información desagregada por centros urbanos para el Censo 2002, la información preliminar ya mencionada para las provincias adyacentes permite inferir que esta tendencia ha persistido.
} 
Este fenómeno está relacionado con la actual modalidad de expansión metropolitana, en la que estas ciudades y pueblos se integran funcionalmente al sistema productivo central, comienzan a cambiar su adscripción laboral y sus estilos de vida cotidianos, y pierden su condición de centros independientes. Todo esto indica que lo que ha estado creciendo hasta ahora con mayor impulso son diversas partes del periurbano vinculadas reticularmente a la ciudad consolidada tradicional. En esta situación, es previsible que la puesta en funcionamiento de nuevas líneas ferroviarias al interior del sistema productivo central (ramales proyectados a Melipilla y a TilTil especialmente), así como la construcción de nuevas autopistas (Nuevo Acceso Norte, Ruta 68 a Valparaíso y Viña del Mar, autopista central, Costanera Norte etc.) seguramente habrán de intensificar en los próximos años esta tendencia, dando renovado impulso a la metropolización expandida y a la ampliación del sistema productivo central.

Por otra parte, a medida que el transporte automotor - y, en particular, el automóvil acentuó su influencia en el proceso de expansión urbana, se intensificó la consolidación de algunos ejes que habían comenzado a perfilarse en el período industrial-desarrollista en torno a las principales vías de transporte que confluían hacia Santiago, por el norte, por el sur y por el poniente. En la medida que algunos de estos ejes se han ido transformando en autopistas, este efecto se ha multiplicado, estableciendo una configuración de desarrollo lineal en torno a la ciudad de tipo tentacular, que contribuye a afirmar algunas de las islas del archipiélago metropolitano.

En forma complementaria, en dirección a la costa del Pacífico se observa la formación de un borde urbano de cerca de 200 kilómetros, desde Santo Domingo al Sur hasta Cachagua al Norte ${ }^{10}$, donde inversiones inmobiliarias destinadas principalmente a segunda residencia de familias del AMS tienden a ir cubriendo las numerosas discontinuidades y vacíos todavía existentes. Al mismo tiempo, como parte del sistema productivo central, se continúa afirmando la conurbación

10 Corresponde a la modalidad de desarrollo urbano por filamentos de la que hablan Dematteis y Governa (2001), que tiene manifestaciones generalizadas en todo el mundo. económica con el área metropolitana de ValparaísoViña del Mar, que incluye importantes ciudades medias como Quilpué, Villa Alemana y Limache; en su conjunto, esta conurbación parece estar destinada a funcionar como aglomeración complementaria del AMS.

\section{IV.3. Creciente policentrismo en la estructura y funcionamiento metropolitano}

La evolución de la metropolización expandida, especialmente desde mediados de la década de los años ochenta, ha estado asociada a un progresivo debilitamiento del papel y de la importancia del centro histórico de la ciudad, lógica consecuencia del continuado aumento de la dimensión y de la extensión metropolitana, bajo la creciente difusión del automóvil y de las NTIC.

Atendiendo las dificultades que se derivaban de la expansión territorial de la aglomeración, el Plan Regulador Metropolitano de 1994 incluyó una propuesta orientada a establecer y consolidar 11 centros o subcentros, conforme a un esquema general de organización urbana que se proponía suministrar y mejorar las condiciones de accesibilidad a servicios públicos y privados en materia de educación, salud, recreación y otros servicios y, al mismo tiempo, reducir los traslados al centro histórico de la población de distintas comunas periféricas. Sin embargo, hasta ahora esta propuesta gubernamental registra escasos avances en tanto que, como contrapartida, lo que ha contribuido en mayor grado a la irrupción y consolidación de nuevas centralidades ha sido, por una parte, la incorporación a la unidad urbana de pueblos y ciudades que hasta entonces habían funcionado en forma independiente $y$, por otra parte, algunas iniciativas privadas de gran dimensión e impacto.

Ha sido así que, como resultado de la conurbación de algunos centros urbanos cercanos, como es el caso de Puente Alto, San Bernardo, Maipú y Quilicura, sus centros pasaron a constituirse en subcentros del espacio metropolitano, en general reforzando sus antiguas funciones centrales con el agregado de nuevas modalidades comerciales. Por otra parte, algunas intervenciones privadas de gran envergadura, como es el caso de algunos shopping malls, de algunas grandes superficies comerciales, así como de ciertas áreas de concentración de funciones empresariales, también han incidido en la estructuración de nuevas centralidades, como ha ocurrido especialmente 
con el Mall Plaza Vespucio, concebido explícitamente como town center en La Florida o el Mall Parque Arauco en Las Condes. A esto cabe agregar que una creciente dispersión de distintos tipos de comercios y de otros servicios, están también inciden en una configuración urbana más extendida y des-centrada, funcional a la creciente difusión y utilización del automóvil, marcando una evolución similar a la que se ha impuesto en las grandes ciudades norteamericanas.

Cabe destacar, sin embargo, que las principales intervenciones privadas con efectos estructurantes en la morfología urbana y en la configuración de nuevas centralidades, en la mayor parte de los casos se han realizado en forma inconexa y fragmentaria y, por lo general, no han mostrado mayor preocupación por considerar las localizaciones más apropiadas desde el punto de vista de la organización y el funcionamiento de la ciudad en su conjunto.

Aun cuando el centro histórico del AMS todavía conserva una elevada concentración de funciones en el área de servicios, el paulatino fortalecimiento en las últimas dos décadas de la dotación de servicios en varios de estos nuevos centros, ha redundado en que para algunas dimensiones de la vida cotidiana aquel haya perdido gravitación y que su utilización sea decreciente para numerosas familias santiaguinas.

\section{IV.4. Formación de áreas periurbanas híbridas}

Un fenómeno que ha comenzado a marcar su presencia en la "otra ciudad" es la aparición de un tipo de espacio ubicado en los intersticios del archipiélago urbano que aún cuando finalmente corresponde a una extensión de los estilos de vida urbanos difícilmente puede calificarse como estrictamente urbano o rural si es que se atienden a las definiciones clásicas al respecto. En lo esencial, resulta de dos tendencias diferentes: por una parte, de la sustitución del trabajador rural tradicional por otro que se mantiene dedicado a labores rurales, pero en diferentes condiciones laborales y residenciales y, por otra parte, del aumento de habitantes urbanos que se desplazan hacia el periurbano en busca de un hábitat diferente, más relacionado con el medio natural (ARMIJO, 2000).

En el caso de la población que se mantiene vinculada a tareas rurales en el ámbito metropolitano, en lo fundamental se observa que ella ha debido hacer frente a importantes cambios con respecto a las condiciones en que trabajaba y habitaba la población rural tradicional en el pasado: por una parte, en su mayor parte se encuentra bajo el predominio del trabajo estacional y precario vinculado a las empresas agro-exportadoras $\mathrm{y}$, por otra parte, está afectada por una creciente urbanización, dado que buena parte de ella reside en las ciudades y pueblos del periurbano metropolitano ubicados en la proximidad de sus lugares de trabajo, lo que a su vez influye en el mayor crecimiento de algunos centros urbanos medianos o pequeños del entorno metropolitano. En estas circunstancias, como afirma Armijo (idem, p. 132), "el asentamiento de la población rural presenta una tendencia general hacia la conglomeración con una clara difusión de valores urbanos".

Por otra parte, al mismo tiempo, en los últimos años se ha intensificado el crecimiento de la ocupación de áreas rurales situadas en la proximidad de la unidad urbana del Gran Santiago por parte de sectores de ingresos medios y altos de la población urbana, que buscan en un hábitat semi-rural condiciones de vida diferentes de las que puede ofrecer la ciudad consolidada. Este es el mundo de las llamadas "parcelas de agrado", que se ha extendido vigorosamente hacia el sur y hacia el norte del Gran Santiago, dando lugar a un negocio inmobiliario en ascenso, que ha llevado al loteamiento de grandes extensiones de tierra periurbana, que hasta no hace mucho estaban plenamente dedicadas a tareas agrícolas.

\section{IV.5. Amplia presencia de nuevos artefactos urbanos}

La nueva base económica, predominantemente terciarizada que emergió junto a la globalización, generó una sostenida demanda por cierto tipo de artefactos urbanos o de nuevas "formaciones socio-espaciales" (MARCUSE \& KEMPEN, 2001, p. 252), cuya irrupción y multiplicación en el Gran Santiago se produjo desde comienzos de la década de los años ochenta. Si bien en muchos casos se trata de un tipo de configuración que ya se había desarrollado y difundido en plena fase fordista en los países centrales y, especialmente, en los Estados Unidos, su irrupción en Chile y en el AMS se produjo solamente cuando las condiciones generadas a partir de la apertura externa y de la globalización justificaron su presencia y otorgaron viabilidad económica a su funcionamiento. 
Estos artefactos aparecen fundamentalmente como resultado del propio desarrollo de un sector servicios globalizado, que a medida que se despliega a escala planetaria plantea la necesidad de un tipo de soporte material-arquitectónico que facilite su adecuado funcionamiento y destaque su presencia urbana; desde esta perspectiva, pueden ser observados como imágenes representativas de las transformaciones que caracterizan el proceso de la globalización de la ciudad (esto es, de su transformación en una "globalizing city"). Así, el AMS ha presenciado la progresiva aparición de la mayoría de los tipos más representativos de estos artefactos, donde en particular cabe destacar los siguientes:

a) centros comerciales diversificados y/o especializados, especialmente shopping malls, cuyas configuraciones de última generación se han adecuado a las prácticas comerciales impuestas por la globalización, de manera de poder albergar a los nodos de numerosas empresas y cadenas globales y, en un proceso de creciente terciarización, suministrar una mixtura servicios análogos a los de las economías centrales: tal es el caso, en especial de los malls Parque Arauco, Plaza Vespucio y Alto Las Condes, que han sido concebidos para cumplir el papel de verdaderos town centers, en la medida que además de incluir los tradicionales patios de comida y complejos de salas de cine, se les han ido incorporando o anexando centros médicos, instalaciones para eventos culturales etc. En estas condiciones, han logrado tener una influencia creciente en la articulación de la vida urbana de sus respectivas áreas de influencia y en la configuración de nuevas centralidades basadas en el potencial de sus espacios públicos de propiedad privada socialmente estratificados;

b) grandes superficies comerciales, tanto para el consumo diversificado (super e hipermercados) como especializado (artículos domésticos y/o para la construcción, el automóvil, la informática etc.) y tiendas de diversos tipos (en especial, numerosos eslabones de cadenas de marcas internacionales), entre las cuales en Santiago de destaca el crecimiento sostenido y la multiplicación de locales de gran dimensión de 3 grandes cadenas de tiendas por departamentos;

c) complejos empresariales y edificios corporativos, concebidos con las más modernas tecnologías ("edificios inteligentes"), muchos de los cuales suelen constituirse en imágenes destacadas de la "otra ciudad". En este sentido, cabría destacar al complejo de grandes edificios corporativo-empresariales que se construyó en una parte del terreno en el que estuvo ubicada la fábrica de la Compañía Cervecerías Unidas en la Comuna de Providencia y cuya construcción marcó uno de los primeros pasos del desplazamiento del centro de negocios de Santiago hacia el oriente de la ciudad. Igual papel ha cumplido el terreno del antiguo Fundo San Luis en la Comuna de las Condes, que al ser ocupados por grandes proyectos inmobiliarios ha tenido una importante influencia en la conformación de uno de los subcentros más dinámicos de la ciudad. Más importante aún por su impacto potencial en la morfología urbana, ha sido la aparición en el AMS de un tipo de complejo empresarial integrado y planificado, del tipo del que Marcuse y Kempen denominan "citadel" y ubican como uno de los rasgos prominentes de las "globalizing cities", que sigue un modelo que se ha venido imponiendo en el mundo entero siguiendo el ejemplo paradigmático de La Defense en Paris o Canary Wharf en Londres; en el caso de Santiago, este tipo de configuración se materializó con la construcción fuera de la mancha urbana consolidada de un ambicioso proyecto denominado "Ciudad Empresarial", destinado a sedes de un gran número de empresas que buscan alejarse del distrito financiero central ${ }^{11}$;

d) hoteles de lujo y súper lujo y conjuntos para la celebración de ferias internacionales, conferencias y grandes eventos, en cuya multiplicación la intensificación de la inserción externa ha tenido una influencia decisiva;

e) configuraciones urbanas para el esparci-miento, frecuentemente asociadas a productos vinculados a las nuevas tecnologías en el campo de la electrónica, entre los que destacan los complejos de salas cinematográficas (multiplex), impulsadas por una rentable asociación entre consumo y cinematografía y los parques temáticos concebidos según las modalidades introducidas por los complejos tipo Disneylandia, y

\footnotetext{
11 Este proyecto considera una inversión prevista del orden de los US\$ 900 millones en más de 100 edificios, de los cuales a octubre del 2000 ya se habían construído 26, lo que determina que su impacto urbano ya sea significativo.
} 
f) barrios cerrados protegidos y segregados, concebidos a imagen y semejanza de los barrios amurallados ("gated communities") de los Estados Unidos, cuya proliferación constituye una respuesta del capital inmobiliario a las nuevas demandas de las familias de ingresos altos y medios, intensificadas por las condiciones establecidas por el aumento de la tasa de motorización y de la progresiva difusión de las NTIC. Complementariamente se aprecia un sostenido aumento de la oferta de edificios de departamentos en altura, principalmente para sectores de ingresos altos y medios, fuertemente concentrados en sus comunas de residencia habitual (especialmente Providencia, Las Condes, Vitacura, Ñuñoa y Santiago), lo que ha redundado en una mayor verticalización de esas comunas y, consecuentemente, en un significativo cambio del respectivo paisaje urbano.

No obstante su relativamente tardía irrupción en Chile y en el AMS en comparación con las economías centrales estas intervenciones urbanas, en sus distintas manifestaciones, se han situado como nuevos íconos de la modernidad y han tenido un poderoso impacto en el funcionamiento y en la organización de la vida urbana de la "otra ciudad", en la "angelinización" de su concepción e imagen y en su reactivación económica. Por un parte, en tanto intervenciones de presencia significativa, contribuyeron a valorizar partes de la ciudad y a reforzar la estructura policéntrica. Por otra parte, también incidieron en la revalorización de la imagen del AMS vis-à-vis otras metrópolis y, por ende, jugaron un importante papel en la promoción de Santiago frente a la competencia interurbana. Y, además, en tanto su construcción y posterior funcionamiento constituye en si mismo una actividad productiva de considerable impacto en la economía metropolitana, han generado importantes efectos en su retroalimentación y, por consiguiente, en el mayor crecimiento relativo de esta aglomeración con relación al resto de las ciudades del sistema urbano chileno.

\section{CONCLUSIONES}

Observando en su conjunto las transformaciones precedentemente consideradas, se puede concluir que, más allá de las diferencias existentes entre Santiago y las ciudades de los países desarrollados, ellas muestran una evolución en la misma dirección que la que se está imponiendo las grandes aglomeraciones urbanas norteameri- canas y europeas ${ }^{12}$. Sin duda se trata de cambios relevantes, que han ido estableciendo diferencias significativas con la ciudad que había cristalizado en la fase culminante del ciclo industrialdesarrollista; ello no obstante, debe reconocerse que muchos de estos cambios constituyen una acentuación y/o culminación de tendencias que ya habían comenzado a esbozarse en la etapa anterior, por lo que esta evolución debe entenderse como el resultado de un proceso de continuidad y cambio. La metamorfosis de la ciudad en cada uno de los períodos relevantes de su historia, se realiza invariablemente a partir de una matriz básica que condiciona su identidad a lo largo del tiempo.

En esa dinámica, los cambios que están llevando a la configuración de esta "otra ciudad" pueden ser entendidos como el resultado de una evolución en la que el nuevo impulso de modernización capitalista reproduce y transforma a la ciudad industrial-desarrollista configurada en el período anterior. En un proceso de esta naturaleza, en cualquier caso, por encima de los impactos de la globalización, las transformaciones resultantes están condicionadas por la identidad que esta ciudad ha desarrollado a lo largo de su historia; vale decir que si bien dichas transformaciones siguen la misma dirección de lo que está ocurriendo en otras grandes aglomeraciones, Santiago mantiene e, incluso, reafirma su personalidad urbana. Así, aún cuando Santiago esté viviendo el mismo tipo de cambios que, por ejemplo, Buenos Aires, Río de Janeiro o Lima, seguirá siendo tan diferente de ellas como lo ha sido hasta ahora.

Desde esta perspectiva, la metrópoli "post" industrial-desarrollista emergente, la "otra ciudad", puede observarse como la lógica, previsible y transitoria culminación de una modalidad de

\footnotetext{
12 Incluso la ciudad europea, mucho más resistente a este tipo de evolución, ha comenzado a transitar en esta dirección, como lo indica Dematteis cuando afirma que "con la periurbanización y la 'ciudad difusa' los modelos de suburbanización de tipo latino-mediterráneo y de tipo anglosajón, que durante mucho tiempo han seguido caminos diferentes, tienden ahora a converger en un modelo único común a toda Europa de 'ciudad sin centro' de estructura reticular, cuyos 'nodos' (sistemas urbanos singulares) conservan y acentúan su identidad a través de procesos innovadores de competición y cooperación" (DEMATTEIS, 1998, p. 17).
} 
urbanización que ha evolucionado al ritmo de un nuevo impulso de modernización capitalista. Esto es, la ciudad industrial-desarrollista, cuya base económica reposaba sobre la industria sustitutiva, está dando paso a una ciudad que corresponde y representa a transformaciones inherentes a una economía crecientemente globalizada e informacionalizada. En particular, ahora los principales cambios responden, por una parte, a la afirmación de una arquitectura productiva en red y a la consecuente transformación de la base económica metropolitana y de su respectivo mercado de trabajo, donde la segmentación parece afirmarse como un rasgo dominante y, por otra parte, a la imposición de un nuevo enfoque de gestión urbana, guiado por los principios de subsidiaridad estatal.

¿Cómo podría caracterizarse entonces a esta "otra ciudad"? En lo esencial, como una ciudad de dinámica reticular, socialmente caracterizada por la persistencia de una polarización que redunda en la intensificación de una segregación residencial ya visible en el período anterior y territorialmente por una continuada dilatación dispersa y discontinua del AMS, cuya mancha urbana desborda sus límites y desdibuja su morfología, conformando una estructura policéntrica de fronteras móviles y marcada por la aparición fragmentaria de un conjunto de artefactos que juegan un papel central en la estructuración del espacio urbano y en la jerarquización de su paisaje e imagen. En esa dinámica, el área en expansión incorpora al funcionamiento cotidiano del sistema productivo central a un número creciente de centros urbanos aledaños y ocupa de manera parcial e incompleta las áreas rurales adyacentes o intersticiales, como un espacio híbrido, compleja mezcla de lo urbano y lo rural. En esta aglomeración emergente, sin duda mucho más imprecisa, más extendida y más difícil de delimitar y de controlar, ya no es tan claro lo que es ciudad y lo que no lo es, aún cuando en su ámbito funcional los modos de vida urbanos se imponen por doquier. Lo que hace realidad la revolución urbana anticipada por Lefebvre, en tanto "el tejido urbano prolifera, se extiende, consumiendo los residuos de vida agraria" (1970, p. 10; itálico en original).

Con lo que puede concluirse que la "otra ciudad" que ha ido emergiendo durante estos años parece estar adoptando en los hechos un modelo de organización y funcionamiento cuyo mejor ejemplo empírico sería Los Angeles, por lo que, poco a poco, habrían comenzado a materializarse en ella algunos de los discursos que, según Soja, caracterizarían a la postmetrópolis: el de laflexcity, como expresión de la emergencia de la especialización flexible; el de la cosmopolis, como cristalización de la globalización del espacio de la ciudad; el de la exópolis, consecuencia de la reestructuración de la forma urbana, caracterizada por el de-centramiento y el re-centramiento del espacio de la ciudad; el de la ciudad fractal, expresión del mosaico social reestructurado, signado por la consecuente emergencia de nuevas formas de metropolaridad, desigualdad y marginalización en medio de una extraordinaria riqueza; el de la ciudad carcelaria, resultante del ascenso de los espacios fortificados, bajo sofisticadas formas y tecnologías de vigilancia, en fin, el de la simcity, expresión de la reestructuración del imaginario urbano como un ciberespacio electrónico, donde la vida urbana se desarrolla como si fuera un juego de computación, donde se confunden las fronteras entre los mundos reales e imaginarios (SOJA, 2000, p. 154ss).

Entender las razones de esta transformación implica tener presente cuales son los factores que guían las decisiones de localización de las actividades productivas y de las familias, cuya influencia es crucial en la determinación de la modalidad e intensidad del crecimiento y la expansión metropolitana. Ello implica, además, aceptar que, en una sociedad capitalista crecientemente liberalizada y desregulada, estas decisiones difícilmente pueden ser controladas o modificadas radicalmente por la voluntad de los gobernantes. En estas circunstancias, es necesario reconocer que la ciudad del pasado, muchas veces tardíamente idealizada y añorada, ya no puede retornar y que los intentos por recuperar dinámicas o formas de esa ciudad, no es más que una ilusión nostálgica sin destino. Como ha ocurrido siempre, será sobre el resultado específico emergente de las condiciones propias de estos nuevos tiempos, que será posible definir alternativas para una gestión para perfeccionar el escenario urbano y su vida cotidiana en la ciudad de los albores del tercer milenio. 
Carlos A. de Mattos (cdmattos@puc.cl) é Pesquisador do Instituto de Estudios Urbanos y Territoriales da Pontificia Universidad Católica de Chile.

\section{REFERÊNCIAS BIBLIOGRÁFICAS}

ARMIJO, G. 2000. La faceta rural de la Región Metropolitana : entre la suburbanización campesina y la urbanización de la élite. EURE, Santiago, v. XXVI, n. 78, p. 131-135, sept.

ASCHER, F. 1995. Métapolis ou l'avenir des villes. Paris : Odile Jacob.

BANCO CENTRAL DE CHILE. 1998. Anuario de cuentas nacionales 1997. Santiago : Banco Central de Chile.

BEAVERSTOCK, J. V., SMITH, R. G. \& TAYLOR, P. J. 1999. A Roster of World Cities. GaWC Research Bulletin, n. 5. http:// info.lboro.ac.uk : 1.noviembre.2002.

CIDU. 1972. Síntesis del estudio Región Central de Chile. Perspectivas de desarrollo. EURE, Santiago, v. II, n. 6, p. 9-30, nov. Centro Interdisciplinario de Desarrollo Urbano y Regional, Equipo Macrozona Central.

CEPAL. 1971. Algunos problemas regionales del desarrollo de América Latina vinculados con la metropolización. Santiago : Comisión Económica para América Latina y Caribe.

CIEPLAN-SUBDERE. 1994. Evolución del producto por regiones 1960-1992. Santiago : Corporación de Investigaciones Económicas para Latinoamérica, Subsecretaría de Desarrollo Regional y Administrativo.

DEMATTEIS, G. 1998. Suburbanización y periurbanización. Ciudades anglosajonas y ciudades latinas. In : MONCLÚS, F. J. (ed.). La ciudad dispersa. Barcelona : Centre de Cultura Contemporània de Barcelona.

1998-1999. Nom basta una forte indentità, la città vive solo se è un 'nodo'. Telèma, n. 15. http://www.fub.it/telema : 01.noviembre.2002.

DEMATTEIS, G. \& GOVERNA, F. 2001. Urban Form and Governance : The New Multi-Centred Urban Patterns. In : ANDERSON, H., JORGENSEN, G., JOYE, D. \& OSTENDORFF, W. (eds.). Change and Stability in Urban Europe. Form, Quality and Governance. Aldershot, UK : Ashgate.
DE MATTOS, C. A. 1999. Santiago de Chile, globalización y expansión metropolitana : lo que existía sigue existiendo. EURE, Santiago, v. XXV, n. 76, p. 29-56, dic.

2001. Movimientos del capital y expansión metropolitana en las economías emergentes latinoamericanas. Revista de Estudios Regionales, Málaga, v. II, n. 60, p. 15-43, mayo-ago.

DUCCI, M. E., DE MATTOS, C. \& GONZALEZ, M. 2002. Area urbana y expansión de Santiago en la última década. Santiago : Instituto de Estudios Urbanos y Territoriales.

FOSSAERT, R. 2001. Les villes mondiales, villes du systeme mondial. Hérodote, Paris, n. 101, p. $10-25,2^{\text {ème }}$ trimestre.

GEDDES, R. 1997. Metropolis Unbound. The Sprawling American City and the Search for Alternatives. The American Prospect, Cambridge, Mass., n. 35, p. 40-46, Nov.-Dec.

GUILHON, B. 1998. Les firmes globales. Paris : Economica.

INE. s/d. Población de los centros poblados de Chile. 1875-1992. Santiago : Instituto Nacional de Estadísticas.

. 1987. Compendio estadístico 1987. Santiago : Instituto Nacional de Estadísticas.

. 1995. Chile. Ciudades, pueblos y aldeas. Censo 1992. Santiago : Instituto Nacional de Estadísticas.

. 1999. V Encuesta de presupuestos familiares. 1996-1997. Santiago : Instituto Nacional de Estadísticas, junio.

.2002. Resultados preliminares. Población y vivienda. Censo 2002. Santiago, Instituto Nacional de Estadísticas. http://www.ine.cl : 01.noviembre. 2002 .

JONAS, A. E. G. \& WILSON, D. 1999. The City as a Growth Machine : Critical Reflections Two Decades Later. In : __ (eds.). The Urban Growth Machine. Albany : State University of New York Press. 
KOLANKIEWICZ, L. \& BECK, R. 2001. Weighing Sprawl Factor in Large US Cities. http://www.sprawlcity.org/studyUSA/ USAsprawlz.pdf : 01.noviembre.2002.

KRUGMAN, P. 1996. Los ciclos en las ideas dominantes con relación al desarrollo económico. Desarrollo Económico, Buenos Aires, v. 36, n. 143 , p. 715-731, oct.-dic.

LAFAY, G. 1996. Comprendre la mondialisation. Paris : Economica.

LEFEBVRE, H. 1972. La revolución urbana. Madrid : Alianza Editorial.

MARCUSE, P. \& KEMPEN, R. (eds.). 2000. Globalizing Cities. A New Spatial Order? Oxford, UK : Blackwell Publishers.

PIZARRO, J. M. 1997. Urbanización, crecimiento urbano y dinámica de la población en las principales ciudades de Chile entre 1952 y 1992. Revista de Geografía Norte Grande, Santiago, n. 24.

MELLER, P. 1996. Un siglo de economía política (1890-1990). Santiago : Andrés Bello.

MENDEZ, R. 2001. Transformaciones económicas y reorganización territorial en la región metropolitana de Madrid. EURE, Santiago, v. XXVII, n. 80, p. 161-161, mayo.

MINGO, O., CONTRERAS, M. \& ROSS, A. 1990. Proyecto Región Capital de Chile. EURE, Santiago, v. XVI, n. 48, p. 7-24, jun.

MIDEPLAN. 1999. Pobreza y distribución del ingreso en Chile. 1990-1998. Santiago : Ministerio de Planificación y Cooperación, División Social.

MINVU. 1981a. Conceptos básicos para la formulación de la Política Nacional de Desarrollo Urbano. EURE, Santiago, v. VIII, n. 22, p. 16-28, sept.

. 1981b. Política Nacional de Desarrollo Urbano. Chile, 1979. EURE, Santiago, v. VIII, n. 22, p. 9-15, sept.

MOLOTCH, H. L. 1976. The City as a Growth Machine. Toward a Political Economy of Place. American Journal of Sociology, v. 2, n. 82, p. 309-330.

OIT. 1998. Chile. Crecimiento, empleo y el desafío de la justicia social. Santiago : Oficina Internacional del Trabajo.

PNUD-MIDEPLAN. 1999. Indice de desarrollo humano en Chile. 1990-1998. Santiago : Programa de las Naciones Unidas para el Desarrollo-Ministerio de Planificación y Cooperación.

2000. Desarrollo humano en las comunas de Chile. Santiago : Programa de las Naciones Unidas para el Desarrollo-Ministerio de Planificación y Cooperación.

RODRÍGUEZ, A. \& WINCHESTER, L. 2001. Santiago de Chile. Metropolización, globalización, desigualdad. EURE, Santiago, v. XXVII, n. 80, p. 121-139, mayo.

RODRIGUEZ VIGNOLI, J. R. 1993. La población del Gran Santiago : tendencias, perspectivas, consecuencias. LC/DEM/R 200, Serie A, n. 283. Santiago : Centro Latinoamericano de Demografía.

SARLO, B. 1994. Escenas de la vida posmoderna. Intelectuales, arte y videocultura en Argentina. Buenos Aires : Ariel.

SASSEN, S. 1994. Cities in a World Economy. London: Pine Forge Press.

SOJA, E. W. 2000. Postmetropolis. Critical Studies of Cities and Regions. Oxford : Blackwell.

SUBDERE-CIEPLAN. 1994. Evolución del producto por regiones, 1960-1992. Santiago : Subsecretaría de Desarrollo Regional y Administrativo-Corporación de Investigaciones Económicas para Latinoamérica.

TOPALOV, C. 1979. La urbanización capitalista. Algunos elementos para su análisis. Ciudad de México : Edicol.

VALDES, A. 1999. Pobreza y distribución del ingreso en una economía en alto crecimiento : Chile, 1987-1995. Estudios Públicos, Santiago, n. 75, p. 5-47, invierno.

VELTZ, P. 1997. L'economie mondiale, une économie d'archipel. En La mondialisation audelà des mythes. Paris : La Decouverte. .2000. Le nouveau monde industriel. Paris : Gallimard. 


\section{OUTRAS FONTES}

El Diario, Santiago, 27.setembro.1991

El Mercúrio, Santiago de Chile, 11.agosto.1993.

El Ladrillo. Bases de la política económica del gobierno militar chileno. 1992. Santiago : Centro de Estudios Públicos.

U_noticias. 2002. Santiago, Universidad de Chile, mar. 
Versão dos resumos para o inglês: Miriam Adelman

\section{DEVELOPMENT AND CAPITALIST ECONOMICS GLOBALIZATION}

\section{Francisco Luiz Corsi (Universidade Estadual Paulista - Marília)}

This article proposes to take an historical inventory of the situation of the countries of the periphery over the last thirty years, looking specifically at the impasses in development belonging to the current phase of so-called globalization of capital. It is based primarily on the study of an extensive literature of recent publication. We ask to what extent the return to development in the various stagnated areas of the periphery can be considered a concrete possibility and engage in a series of reflections around this issue, which we consider as fundamental for the present conjuncture. We seek to show that the economic stagnation that characterizes many non-developed countries is due in part to the social and economic crisis that began in the decade of the seventies and continues to date, efforts to restructure capitalist society notwithstanding. Strategies and policies of a neo-liberal type have also contributed significantly to this situation, to the extent that they have reinforced the financial knots that have suffocated a large portion of the peripheral economies. Adding to these problems, such countries have also been faced with the ecological limits of capitalism. Reinitiating development on another plane, involving economic growth, social justice and the preservation of nature would mean breaking with capitalism itself.

KEYWORDS: development; globalization; national project; social and economic crisis.

\section{SANTIAGO DE CHILE FACES GLOBALIZATION: ANOTHER CITY?}

\section{Carlos A. de Mattos (Pontificia Universidad Católica de Chile)}

This paper proposes to identify and characterize the "other city" that has sprung from the transformations taking place in the metropolitan area of Santiago de Chile. These changes are a result of a new macro-economic strategy adopted from the middle of 1970 in which growing economic liberalization as well as a wide opening-up to the exterior promoted increased globalization of the national economy. Within this context, we see that together with significant changes in the metropolitan area's economic base came a radical re-structuring of its labor market and a greater territorial dispersion of productive activities and population. Against the backdrop of this new scenario, we look at how the changes that effected this emerging city have confirmed, on the one hand, a social morphology based on polarization and residential segregation and on the other, a territorial morphology based on suburbanization and multiple centers. These changes correspond to the tendencies that can be observed today in all large metropolitan areas, both within the core countries and the emerging economies.

KEYWORDS: globalization; informality; metropolitanization; suburbanization; multiple centers; residential segregation.

\section{GLOBALIZATION AND DIRECT FOREIGN INVESTMENT: AN EXPLORATORY STUDY OF THE BRAZILIAN AUTOMOBILE INDUSTRY}

Ana Lucia Guedes (Pontifícia Universidade Católica do Paraná)

Alexandre Faria (Pontifícia Universidade Católica do Paraná)

This article presents preliminary results of research that aims to develop a theoretical framework to analyze the antecedents and implications of economic globalization in Brazil. More specifically, the article focuses on questions of governing and environmental sustainability related to the direct foreign 
Versão dos resumos para o francês: Maria Fernanda Araújo Lisbôa

\section{LE DEVELOPPEMENT À LA LUMIERE DE LA GLOBALISATION DE L'ECONOMIE CAPITALISTE}

Francisco Luiz Corsi (Universidade Estadual Paulista - Marília)

Cet article cherche à dresser, sous la perspective historique, le bilan de la situation des pays périphériques dans les dernières trentes années. Pour cela, il aborde particulièrement les enjeux du développement dans la phase de la globalisation du capital. Ce travail s'appuie surtout sur les études de la vaste bibliographie publiée récemment. Dans quelle mesure la relance du développement concernant plusieurs secteurs stagnés de la périphérie deviendrait-elle une réelle possibilité? Autour de cette question, que nous trouvons centrale dans l'actuelle conjoncture, nous entamons quelques réflexions. Nous envisageons montrer que la stagnation économique à laquelle des nombreux pays non développés font face ne découle pas en partie d'une crise sociale et économique ouverte dans les années soixante-dix et qui s'élargit jusqu'à nos jours malgré les tentatives de restructuration de la société capitaliste. Les stratégies et les mesures politiques à caractère néo-liberal aussi auraient énormément contribué à cette situation étant donné qu'elles ont renforcé les amarres financières qui ont étranglé pour une part les économies périphériques. Outre ces difficultés, ces pays affronteraient les limites écologiques du capitalisme. La relance du développement dans un nouveau stade exigeant la croissance économique, la justice sociale et la préservation de la nature amènerait à une rupture face au capitalisme.

MOTS-CLÉS: développement; globalisation; projet national; crise socioéconomique.

\section{SANTIAGO DU CHILI FACE À LA GLOBALISATION: UNE AUTRE VILLE?}

Carlos A. de Mattos (Pontificia Universidad Católica de Chile)

Ce travail a pour but d'identifier et de caractériser "l'autre ville" originaire des transformations qui ont touché la ville de Santiago en fonction de l'assomption, à partir du milieu des années 1970, d'une nouvelle stratégie macroéconomique, où non seulement une croissante libéralisation économique mais aussi une vaste ouverture externe ont favorisé la progressive globalisation de l'économie nationale. Dans ce contexte, on observe comment parallèlement aux importantes modifications de la base économique de la ville a commencé à se mettre en place une restructuration radicale de son marché du travail et un plus grand éparpillement territorial des activités productives et de la population. Dans ce nouveau décor, on analyse comment les transformations qui ont touché la ville émergente ont influencé l'affirmation, d'une part, d'une morphologie sociale où persiste la polarisation sociale et la ségrégation résidentielle et, d'autre part, d'une morphologie territoriale où la sous-urbanisation et la policentralité l'emportent. Ces transformations correspondent aux tendances qu'on observe actuellement sur les aires métropolitaines non seulement dans les pays au centre mais aussi dans les économies émergentes.

MOTS-CLÉS: globalisation, informalité; métropolisation; sous-urbanisation; policentrisme; ségrégation résidentielle.

GLOBALISATION ET INVESTISSEMENT DIRECT ETRANGER: UNE ETUDE EXPLORATOIRE DE L'INDUSTRIE AUTOMOBILE BRESILIENNE

Ana Lucia Guedes (Pontifícia Universidade Católica do Paraná)

Alexandre Faria (Pontifícia Universidade Católica do Paraná) 